serie Vertical Foreign Direct Investment: Make, Sell and (Not) Buy 
Los documentos de trabajo del Ivie ofrecen un avance de los resultados de las investigaciones económicas en curso, con objeto de generar un proceso de discusión previo a su remisión a las revistas científicas. Al publicar este documento de trabajo, el Ivie no asume responsabilidad sobre su contenido.

Ivie working papers offer in advance the results of economic research under way in order to encourage a discussion process before sending them to scientific journals for their final publication. Ivie's decision to publish this working paper does not imply any responsibility for its content.

La Serie AD es continuadora de la labor iniciada por el Departamento de Fundamentos de Análisis Económico de la Universidad de Alicante en su colección "A DISCUSIÓN" y difunde trabajos de marcado contenido teórico. Esta serie es coordinada por Carmen Herrero.

The AD series, coordinated by Carmen Herrero, is a continuation of the work initiated by the Department of Economic Analysis of the Universidad de Alicante in its collection "A DISCUSIÓN", providing and distributing papers marked by their theoretical content.

Todos los documentos de trabajo están disponibles de forma gratuita en la web del Ivie http://www.ivie.es, así como las instrucciones para los autores que desean publicar en nuestras series.

Working papers can be downloaded free of charge from the Ivie website http://www.ivie.es, as well as the instructions for authors who are interested in publishing in our series.

Versión: abril 2017 / Version: April 2017

Edita / Published by:

Instituto Valenciano de Investigaciones Económicas, S.A.

C/ Guardia Civil, 22 esc. $21^{\circ}-46020$ Valencia (Spain)

DOI: http://dx.medra.org/10.12842/WPAD-2017-02 
WP-AD 2017-02

\title{
Vertical Foreign Direct Investment: Make, Sell and (Not) Buy*
}

\author{
Chrysovalantou Milliou and Joel Sandonis**
}

\begin{abstract}
According to conventional wisdom, multinational firms undertake vertical FDI in order to take advantage of cross-border factor cost differences and source the inputs from abroad at better terms. Recent empirical findings though document that this is not always the case. We provide theoretical support to the latter by demonstrating that when there is transfer of intangible assets between a multinational's vertically related production plants, its parent firm can engage in vertical FDI in order to improve its cross-threat and its input sourcing terms domestically and not abroad as well as in order to exploit its intangible assets in another country. We also investigate the effects of trade liberalization and the welfare consequences of vertical FDI.
\end{abstract}

Keywords: international trade; vertical FDI; inputs; trade liberalization; intangible assets; two-part tariffs.

JEL classification numbers: L13; L22; L23; F12; F23.

\footnotetext{
* We would like to thank Ozlem Bedre-Defolie, Claire Chambolle, Ramon Faulí-Oller, Ines Macho-Stadler, Joao Montez, Hans-Theo Normann and Emmanuel Petrakis for their useful suggestions. We would also like to thank the participants at the XIV International Industrial Organization Conference at Philadelphia, the Workshop on Vertical Related Markets at Dusseldorf, the XXXV ASSET Meeting at Granada, the CRETE 2016 at Tinos, the XXXVIII Simposio de Análisis Económico at Girona, the Workshop on Competition in Vertical Chains in Toulouse, the Oligoworkshop 2016 at Paris, the XXXI JEI at Palma and the 2016 EARIE Conference at Lisbon for their comments. Full responsibility for all short comings is ours.

** C. Milliou: Department of International and European Economic Studies, Athens University of Economics and Business, Athens 10434, Greece, e-mail: cmilliou@aueb.gr; Corresponding author: J. Sandonis: Department of Economics, University of Alicante, Alicante 03080, Spain, e-mail: sandonis@,ua.es.
} 


\section{Introduction}

The international specialization of production and the organization of firms' production activities on a global scale both constitute by now well-established phenomena. This is reflected in the significant increase of inputs trade and of foreign direct investment (FDI) during the last decades. ${ }^{1}$ In fact, many recent empirical studies reveal that trade in inputs has outpaced trade in final products and that a large share of FDI comprises of vertical FDI. ${ }^{2}{ }_{3}$

Traditionally, the literature has argued that firms undertake vertical FDI in order to take advantage of cross-country factor cost differences associated, for instance, with the abundance of unskilled labor in developing countries (Helpman, 1984; Helpman and Krugman, 1985). Stated differently, multinational enterprises (MNEs) establish affiliates in countries with lower input production costs than their home countries so that their parent firms source the inputs from the former at better terms.

Recent data, however, do not provide support to the traditional explanation for vertical FDI. They show that there are many instances in which little, if any, intra-firm trade occurs between a MNE's parent firm and its vertically related affiliates and/or in which vertical FDI takes place among countries with similar characteristics. ${ }^{4}$ In particular, Ramondo et al. (2016), focusing on U.S. multinational firms, document, first, that the median shipment size of a foreign affiliate to its vertically related parent firm is zero, and second, that the median foreign affiliate ships $91 \%$ of its production to unaffiliated parties mostly within its country of operation. ${ }^{5}$ Moreover, Alfaro and Charlton (2009), using detailed sectoral data for 400 industries and 90 countries, find a substantial amount of vertical FDI between rich countries, in high-skill sectors involving products that are at stages closer to the parent firms' final production stage. Based on this, they conclude that the main motivation for vertical FDI is not the lower production cost of the host countries.

\footnotetext{
${ }^{1}$ For empirical evidence regarding the increase in inputs trade see e.g., Feenstra (1998), Feinberg and Keane (2001), Hummels et al. (2001), Yeats (2001), Yi (2003), Hanson et al. (2005). The increase in both the volume and the growth rate of FDI relative to the world GDP is extensively documented in multiple reports of the United Nations (e.g., UNCTAD, 2001, 2006, 2014).

${ }^{2}$ Vertical FDI corresponds to the establishment of an affiliate abroad that operates at a different stage of the vertical production chain than the one in which the parent firm operates.

${ }^{3}$ Yeaple (2003), Hanson et al. (2005), Alfaro and Charlton (2009) and Ramondo et al. (2016) document that vertical FDI is far more prevalent than previosouly thought (e.g., Brainard, 1997; Carr et al., 2001). In fact, Alfaro and Charlton (2009) find that vertical FDI exceeds the $52 \%$ of the total FDI.

${ }^{4}$ We should note still that intra-firm trade constitutes a large fraction of the total world trade (e.g., Slaughter, 2000; Bas and Carluccio, 2015).

${ }^{5}$ A similar pattern has been identified by Atalay et al. (2014) in the case of the domestic operations of U.S. multi-plant firms: the vertical links between their affiliates located within the U.S. are not associated with significant intra-firm shipments. As argued by Ramondo et al. (2016), this pattern is more striking in the case of cross-border trade since factor cost differences tend to be larger across countries.
} 
The above evidence suggest that we should reconsider the conventional wisdom regarding vertical FDI. They raise questions regarding the potential motives behind it, and in particular, regarding the reasons that some MNEs own internationally segmented production chains if not for the transfer of goods along them. In this paper, we address these questions. In particular, we explore the incentives for vertical FDI allowing for endogenous input sourcing decisions, i.e., without presuming that there is intra-firm trade within the MNEs.

To do so, we use a partial equilibrium framework with two countries, a home country and a foreign country, and two stages of production, an upstream stage and a downstream stage. In each country, there is an upstream firm (input producer) and a downstream firm (final product manufacturer). The foreign upstream firm can be either more or less efficient than the home one. The home downstream firm decides whether it will undertake vertical FDI by acquiring the foreign upstream firm. In case of vertical FDI, it transfers its intangible assets to its acquired subsidiary. This transfer can enhance the latter's efficiency. ${ }^{6}$ In the absence of vertical FDI, both downstream firms choose among domestic outsourcing and offshoring, corresponding respectively to input sourcing from the domestic upstream firm and from the foreign upstream firm. In the presence of vertical FDI, the home downstream firm chooses among outsourcing and importing the input from its own foreign affiliate - insourcing. We assume that a tariff is imposed on the imported inputs and that the non-integrated vertically related firms trade through two-part tariff contracts.

We demonstrate that a downstream firm opts for outsourcing when the domestic upstream firm is more efficient than the foreign one as well as when it is less efficient but the tariff is sufficiently high. This holds both in the absence and in the presence of vertical FDI. Therefore, when a downstream firm undertakes vertical FDI - when it makes the input, it is not necessary that it does not buy the input. In other words, just like in the empirical findings of Ramondo et al. (2016), vertical FDI is not always accompanied by intra-firm trade. There are instances in which the MNE makes the input and it either sells and buys it or it does not sell and (not) buys it, depending on the relative input production costs and the tariff level.

Vertical FDI arises in equilibrium whenever the transfer of intangible assets from the MNE's parent firm to its upstream affiliate is effective. This occurs even in the absence of intra-firm

\footnotetext{
${ }^{6}$ This assumption is in line with the empirical findings of Arnold and Javorcik (2009), who use Indonesian firm-level data and find that foreign acquisitions have a positive impact on the productivity of the acquired plants. The authors conclude that the productivity boost is achieved through restructuring involving, among other things, the introduction of organizational and managerial changes that make the production process more efficient by reducing waste and using labor more effectively. Moreover, this assumption is indirectly supported by empirical studies that find that upstream FDI results in possitive forward spillovers, and thus, in an increase in the productivity of the host country's downstream firms (e.g., Girma et al., 2008; Newman et al., 2015).
} 
trade under vertical FDI. The intuition is as follows. When both downstream firms opt for outsourcing under vertical FDI - in the make, sell and buy case, vertical FDI is motivated by the simultaneous presence of two effects: the assets exploitation effect and the outsourcing terms effect. The first effect refers to the fact that vertical FDI allows the MNE's parent firm to take advantage of its intangible assets in another country besides its home country. In particular, through the enhancement in the efficiency of the MNE's foreign affiliate, vertical FDI leads to (more) input sales, and thus, to profits from the foreign country. The second effect, the outsourcing terms effect, corresponds to the improvement in the terms at which the MNE's parent firm sources the input domestically. The better input sourcing terms result from the increase in its outside option - its cross-threat in its trading with the home upstream firm as a result of the rise in its foreign affiliate's efficiency.

Interestingly, the home downstream firm has incentives to acquire the foreign upstream firm even in the (make), not sell and buy case, that is, even when the foreign upstream firm makes no sales and thus no profits after the acquisition. This happens when the foreign country is less efficient than the home country and the tariff is sufficiently low. In other words, vertical FDI can arise even when the differences in the factors cost across countries work against it. In such a case, vertical FDI is motivated by the outsourcing terms effect alone; the MNE undertakes vertical FDI just in order to secure better input sourcing terms domestically and not abroad.

When both downstream firms source the input from the foreign upstream firm - in the make, sell and not buy case, vertical FDI is motivated instead by the assets exploitation effect together with the insourcing terms effect. The latter effect is in accordance with the conventional wisdom regarding vertical FDI. It refers to the fact that vertical FDI leads to an improvement in the terms at which the MNE's parent firm sources the input from its foreign affiliate. Note though that the better input sourcing terms do not arise from the disappearance of the positive mark-up on the input price, which is absent under trading through two-part tariffs; they arise from the enhancement in the internal supplier's efficiency.

If the transfer of intangible assets is not effective, all the above mentioned effects are absent and the incentives for vertical FDI disappear. Therefore, it is important to take into account the transfer of intangible assets not only within a MNE's horizontally related production plants, but also within its vertically related plants. ${ }^{7}$ This conclusion is supported by the empirical results of Atalay et al. (2014), who find that one of the primary purposes for vertical ownership is the facilitation of the efficient transfer of intangible inputs within the firms.

\footnotetext{
${ }^{7}$ Most of the papers on horizontal FDI assume that the MNE's parent firm transfers to its foreign affiliate its intangible assets (e.g., Petit and Sanna-Randaccio, 2000; Mattoo et al., 2004).
} 
Trade liberalization, captured by a reduction in the tariff level, can increase not only the volume of inputs trade but also the incentives for vertical FDI. More specifically, a tariff reduction can lead to an improvement in the input sourcing terms of the MNE's parent firm either through the enhancement in its cross-threat under outsourcing or through the reduction in its trade cost under insourcing. The only drawback that trade liberalization can have for vertical FDI is that in certain cases it weakens the intensity of the assets exploitation effect by causing a switch in the foreign downstream firm's input supplier from the foreign one to the home one.

Our welfare analysis reveals that vertical FDI, and thus, vertical cross-border mergers and acquisitions (M\&As) although they can never harm the consumers of neither the home or the host country, they can, under certain conditions, have a negative effect on a country's total welfare. In the case, of the home country this could arise from the decrease in the profits of its upstream firm caused by the increase in the efficiency of its rival. In the case of the foreign country instead, the negative welfare impact could result from the loss of its tariff revenues: vertical FDI increases the efficiency of the foreign upstream firm and thus reduces the input imports from abroad and the resulting tariff revenues. Interestingly, the welfare implications of vertical FDI on the two countries are not always aligned; vertical FDI can at the same time be welfare-enhancing for one country and welfare-dampening for the other. Clearly, this gives rise to a number of issues regarding the treatment of cross-border M\&As by national or supranational competition policy authorities.

Our paper is related to a growing literature that combines elements of the economics of organization and of international trade and examines how firms organize their production in the global economy. A number of papers within this literature deal with the choice between various global sourcing options (e.g., Qiu and Spencer, 2002; Grossman and Helpman, 2003 and 2005; Antras and Helpman, 2004; Chen et al., 2004; Ornelas and Turner, 2008; Berry and Kaul, 2015), such as between offshoring and vertical FDI or between outsourcing, in-house production and offshoring. ${ }^{8,9}$ This literature builds on the assumption that inputs are produced at lower cost abroad and that there is intra-firm trade under vertical FDI. Doing so, it explains the vertical FDI which is directed towards developing countries as well as the high percentage of intra-firm trade within total trade. But, it does not explain vertical FDI from and towards rich countries and/or the many instances in which there is no transfer of goods among the MNEs'

\footnotetext{
${ }^{8}$ Some of these papers perform their analysis using a general equilibrium framework (e.g., Grossman and Helpman, 2003 and 2005; Antras and Helpman, 2004). Others instead, similarly to our paper, use a partial equilibrium setting (e.g., Qiu and Spencer, 2002; Chen et al., 2004; Ornelas and Turner, 2008; Berry and Kaul, $2015)$.

${ }^{9}$ In some papers, offhsoring and outsourcing are referred to as foreign outsourcing and domestic outsourcing respectively. See Spencer (2005) and Antras and Rossi-Hansberg (2009) for a review of this literature.
} 
internationally fragmented productions plants.

In our paper, we do not restrict our attention to cases in which the cross-country factor cost differences work in favor of vertical FDI. In addition, we do not treat the input source of vertically integrated MNEs as exogenous: a firm, even when it makes the input, is free to decide whether or not it will buy it from an external supplier. Removing these restrictions, we perform an in-depth exploration of the motives for vertical FDI and provide theoretical support to recent empirical findings. In addition, we evaluate the welfare implications of vertical FDI and discuss its desirability from the viewpoint of both the home and the host country. ${ }^{10}$

Our paper is also associated with the industrial organization literature on strategic outsourcing (e.g., Nickerson and Vanden Bergh, 1999; Shy and Stenbacka, 2003). This literature has explored the incentives and implications of the choice among in-house production and outsourcing - the make-or-buy decision, as well as it has studied a number of alternative input sourcing strategies, such as bi-sourcing (e.g., Du et al., 2006 and 2009; Beladi and Mukherjee, 2012; Stenbacka and Tombak, 2012). An important distinction from our paper is that the strategic outsourcing literature allows only for domestic and not for cross-border vertical integration. $^{11}$

The rest of the paper proceeds as follows. In Section 2, we describe our main model. In Section 3, we analyze firm's input sourcing decisions both with and without vertical FDI. In Sections 4 and 5, we explore respectively the incentives for vertical FDI and how they can be influenced by trade liberalization. In Section 6, we consider the welfare implications of vertical FDI. In Section 7, we extend our analysis in various directions. In the final section, Section 8 , we conclude. All the proofs are relegated to the Appendix.

\section{The Model}

We consider a partial equilibrium model with two countries, a home country $H$ and a foreign country $F$, and two stages of production, an upstream stage and a downstream stage. Initially, in each country $i$, with $i=H, F$, there is a domestic upstream firm, $U_{i}$, and a domestic downstream firm, $D_{i}$. The upstream firms produce an input which the downstream firms use in a one-to-one proportion in the production of their final products. We assume that $U_{i}$ produces the input at

\footnotetext{
${ }^{10}$ In this respect, our paper is also related to the literature that examines the welfare impliactions of mergers in open economies (e.g., Keith and Ries, 1997; Breinlich et al., 2016), that is, of mergers that affect the welfare of multiple countries.

${ }^{11}$ Extending our analysis, in Section 7, we explore the choice between domestic and cross-border vertical integration.
} 
constant marginal cost $c_{i}$ and that either of the two countries can be more efficient in input production, i.e., $c_{H}>c_{F}$ or $c_{H}<c_{F}$.

Each $D_{i}$ sells its final product exclusively in the market of country $i^{12}$ The (inverse) demand function for the final product in country $i$ is given by $p\left(q_{i}\right)$. We assume that $p\left(q_{i}\right)$ is well-behaved: it is continuous, twice differentiable, and concave.

Each $D_{i}$ can source the input domestically from $U_{i}$ or it can import it from $U_{j}$, with $i, j=$ $H, F$ and $i \neq j$. In either case, $D_{i}$ trades with its input supplier, $U_{k}$, with $k=H, F$, through a two-part tariff contract: $D_{i}$ pays to $U_{k}$ a wholesale price per unit of input, $w_{i k}$, and a fixed fee, $F_{i k}$. In the case of input imports, $D_{i}$ incurs an additional unit cost, the tariff imposed on the imported goods, $t$, with $p(0)-c_{i}>t>0$.

$D_{H}$ considers engaging in vertical FDI. More specifically, it considers acquiring $U_{F} \cdot{ }^{13,14}$ When it decides to do so, it makes a take-it-or-leave-it acquisition offer to $U_{F}$ : it specifies an acquisition price, $A$. When the offer is accepted, $D_{H}$ transfers its intangible assets to its upstream affiliate, $U_{F} \cdot{ }^{15}$ This transfer can lead to a reduction in $U_{F}$ 's local marginal cost from $c_{F}$ to $\widehat{c}_{F}$, with $0 \leq \widehat{c}_{F} \leq c_{F}$. From now on, we will say that the transfer of assets is effective whenever $\widehat{c}_{F}<c_{F}$.

We analyze a three-stage game in which, in the first stage, $D_{H}$ decides whether it will undertake vertical FDI, and thus, whether it will make an acquisition offer to $U_{F}$. When it makes an offer, $U_{F}$ decides subsequently whether to accept or reject it. In the second stage, $U_{H}$ and $U_{F}$ make simultaneously and separately their take-it-or-leave-it offers regarding the terms of trade. Both upstream firms make offers to both downstream firms under no vertical FDI, whereas under vertical FDI, since $U_{F}$ is vertically integrated with $D_{H}$, it makes an offer only to $D_{F}$. In the last stage, $D_{H}$ and $D_{F}$ simultaneously and separately decide from which upstream firm they will source the input. Under no vertical FDI, both downstream firms choose between sourcing the input domestically - outsourcing - and importing the input - offshoring. Under vertical FDI, $D_{H}$ chooses among outsourcing and sourcing the input internally from its foreign

\footnotetext{
${ }^{12}$ This could be due to the fact that the transfer of the final product is very costly. Alternatively, it could be due to the nature of the final product which dictates immediate and/or local consumption. The latter is often the case in the food retailing market, in the construction market as well as in many markets in the services sector (e.g., accommodation market, telecommunications market).

${ }^{13}$ We exclude FDI through the establishment of a new production plant abroad - Greenfield Investment. Greenfield Investment is excluded either because it requires a prohibitively high fixed set-up cost or because the knowhow and/or the raw materials that are necessary for input production are exclusively in the hands of the incumbent upstream firm.

${ }^{14}$ Cross-border M\&As constitute a quite common form of FDI. In the period 2005-2015, their annual share within the total FDI exceeded on average 30\%. In fact, in 2007, more than half of FDI took place through cross-border M\&As.

${ }^{15}$ The transfer of assets among the MNEs' parent firms and affiliates is a common feature of FDI.
} 
upstream affiliate - insourcing. In the same stage, each downstream firm chooses the level of its output.

As a tie-breaking rule, we assume that vertical FDI arises in equilibrium only if $D_{H}$ 's profits are strictly higher with than without vertical FDI. This assumption can be justified, for instance, when vertical FDI entails additional fixed costs (e.g., administrative costs).

\section{$3 \quad$ Input Sourcing Strategies}

In the last stage of the game, each $D_{i}$ faces the standard monopolist's problem in the market of its domestic country $i$. More specifically, each $D_{i}$ chooses $q_{i}$ in order to maximize its (gross from the acquisition price) profits:

$$
\max _{q_{i}} \pi_{D_{i}}\left(q_{i}\right)=\left(p\left(q_{i}\right)-C_{i k}\right) q_{i}-F_{i k},
$$

where $C_{i k}$ is the total marginal cost faced by $D_{i}$ when it sources the input from $U_{k}$. In particular, $C_{i i}=w_{i i}$ under outsourcing, $C_{i j}=w_{i j}+t$ under offshoring, and $C_{H F}=c_{F}+t$ under insourcing. Solving (1), we obtain $D_{i}$ 's equilibrium output, $q_{i}^{*}\left(C_{i k}\right)=\arg \max \pi_{D_{i}}\left(q_{i}\right)$, and subsequently, $D_{i}$ 's equilibrium profits in terms of the input's cost:

$$
\pi_{D_{i}}\left(C_{i k}, F_{i k}\right)=\left(p\left(q_{i}^{*}\left(C_{i k}\right)\right)-C_{i k}\right) q_{i}^{*}\left(C_{i k}\right)-F_{i k} .
$$

$D_{i}$ 's input sourcing decision depends, among other things, on whether vertical FDI has taken place. In what follows, we analyze in detail both the case with and without vertical FDI. We will use the superscripts $N$ and $V$ respectively to refer to the "no vertical FDI" and to the "vertical FDI" case.

\subsection{No Vertical FDI}

Under no vertical FDI, both downstream firms source the input only externally. Recall that they do so through a non-linear contract and without competition among them. In such a case, it is known from the literature (e.g., O' Brian and Shaffer, 1997) that an upstream firm maximizes, through the wholesale price, its stand-alone joint profits with its downstream customer and

extracts, through the fixed fee, their highest possible share. Here, the stand-alone joint profits of the $\left(U_{k}, D_{i}\right)$ pair are:

$$
\pi_{U_{k} D_{i}}\left(w_{i k}, F_{i k}\right)=\left(w_{i k}-c_{k}\right) q_{i}^{*}\left(C_{i k}\right)+F_{i k}+\pi_{D_{i}}\left(C_{i k}, F_{i k}\right) .
$$


One can easily see that (3) is maximized when $w_{i k}^{N}=c_{k}$. Hence, the maximized stand-alone joint profits of the $\left(U_{k}, D_{i}\right)$ pair are $\pi_{U_{k} D_{i}}\left(C_{i k}\right)=\left(p\left(q_{i}^{*}\left(C_{i k}\right)\right)-C_{i k}\right) q_{i}^{*}\left(C_{i k}\right)$, with $C_{i k}=c_{k}$ under outsourcing and $C_{i k}=c_{k}+t$ under offshoring. From the Envelope Theorem, we have:

$$
\frac{d \pi_{U_{k} D_{i}}\left(C_{i k}\right)}{d C_{i k}}=\frac{\partial \pi_{U_{k} D_{i}}\left(C_{i k}\right)}{\partial C_{i k}}=-q_{i}^{*}\left(C_{i k}\right)<0
$$

Therefore, the higher is $C_{i k}$, the lower are the $\left(U_{k}, D_{i}\right)$ pair's maximized stand-alone joint profits.

Suppose now that $D_{i}$ 's maximized stand-alone joint profits with one of the upstream firms are larger than its respective profits with the other upstream firm, e.g., $\pi_{U_{H} D_{i}}\left(C_{i H}\right)>\pi_{U_{F} D_{i}}\left(C_{i F}\right)$. Then, the equilibrium contract offers are $\left(w_{i H}^{N}, F_{i H}^{N}\right)=\left(c_{H}, \pi_{U_{H} D_{i}}-\pi_{U_{F} D_{i}}\right)$ and $\left(w_{i F}^{N}, F_{i F}^{N}\right)=$

$\left(c_{F}, 0\right)$. A consequence of this is that $\pi_{D_{i}}^{N}\left(C_{i H}, F_{i H}^{N}\right)>\pi_{D_{i}}^{N}\left(C_{i F}, F_{i F}^{N}\right)$, and thus, that $D_{i}$ sources the input from $U_{H}$. In other words, in equilibrium, the upstream firm that achieves the greatest stand-alone joint profits with $D_{i}$ compensates the latter by more than its rival can and becomes its input supplier. In fact, the profits that $U_{H}$ extracts, through $F_{i H}$, are equal to its incremental contribution to its stand-alone joint profits with $D_{i}$. Attempting to extract more would make $D_{i}$ choose the rival supplier, while extracting less would not maximize the supplier's profits, leaving surplus on the table.

In light of the above, Lemma 1 summarizes the equilibrium input sourcing decisions of the downstream firms under no vertical FDI.

Lemma 1 Under no vertical FDI, $D_{i}$ chooses offshoring if $c_{i}>c_{j}+t$ and outsourcing otherwise.

In the absence of vertical FDI, a downstream firm opts for offshoring if and only if the domestic input supplier is less efficient than the foreign one and international trade is not too costly. The intuition is straightforward. Recall that the maximized stand-alone joint profits of $D_{i}$ with $U_{k}$ decrease with the former's total marginal cost $C_{i k}$. Recall also that $C_{i k}=c_{k}$ and $C_{i k}=c_{k}+t$ respectively under outsourcing and offshoring. Clearly, when $c_{j}<c_{i}$ and $t$ is sufficiently low, then $C_{i j}<C_{i i}$ and the joint profits of the $\left(U_{j}, D_{i}\right)$ pair are higher than those of the $\left(U_{i}, D_{i}\right)$ pair; hence, in equilibrium $U_{j}$ compensates $D_{i}$ more than $U_{i}$ can and becomes its input supplier.

\subsection{Vertical FDI}

Under vertical FDI, $D_{H}$ can insource the input from $U_{F}$ facing marginal cost $\widehat{c}_{F}+t$ or it can outsource it from $U_{H}$ and pay the endogenously determined $\left(w_{H H}, F_{H H}\right)$. Consequently, when $U_{H}$ makes its contract offer to $D_{H}$, it is aware of the latter's outside option: the profits that $D_{H}$ makes in country $H$ when it rejects its offer. This leads again to $w_{H H}^{V}=c_{H}$ and to 
$F_{H H}^{V}=\max \left\{0, \pi_{U_{H} D_{H}}\left(C_{H H}\right)-\pi_{U_{F} D_{H}}\left(C_{H F}\right)\right\}$.

At the same time, $D_{F}$ can source the input from either $U_{H}$ or $U_{F}$. Competition among the latter leads to the same equilibrium terms of trade as in the no vertical FDI case. The only difference is that now the marginal cost that $D_{F}$ faces under outsourcing is $\widehat{c}_{F}$ instead of $c_{F}$.

Taking the above into account, we determine in Lemma 2 the equilibrium input sourcing decisions of the downstream firms under vertical FDI.

\section{Lemma 2 Under vertical FDI,}

(i) $D_{H}$ chooses insourcing if $c_{H}>\widehat{c}_{F}+t$ and outsourcing otherwise.

(ii) $D_{F}$ chooses offshoring if $\widehat{c}_{F}>c_{H}+t$ and outsourcing otherwise.

When a downstream firm undertakes vertical FDI, it does not always source the input from its foreign upstream affiliate. Thus, the fact that under vertical FDI the MNE makes the input does not necessarily mean that it also does not buy the input. This conclusion comes in contrast with the commonly used assumption in the existing literature that under vertical FDI, the MNE's parent firm sources the input from its foreign upstream affiliate. However, it is in line with a number of recent empirical studies (see e.g., Ramondo et al., 2016, Atalay et al., 2014) which show that often there is no transfer of inputs between the parent firms and their vertically related subsidiaries.

A straightforward implication of Lemma 2(i) is that the more efficient is the MNE's upstream affiliate, i.e., the lower is $\widehat{c}_{F}$ either because the initial $c_{F}$ is quite low or because it drops a lot by the transfer of assets, the more likely is that intra-firm trade will be observed. This conclusion, besides being quite intuitive, is in accordance with another empirical observation of Ramondo et al. (2016); the observation that large, and thus more efficient, affiliates are substantially more likely to ship goods to their parent firms.

Combining Lemma 2 with Lemma 1, we draw three additional conclusions. The first conclusion is fully intuitive: when vertical FDI is accompanied by an effective transfer of assets, $D_{H}$ is more likely to source the input from abroad with than without vertical FDI. Formally, $c_{H}>\widehat{c}_{F}+t$ is a weaker condition relative to $c_{H}>c_{F}+t$. Clearly, the more effective is the transfer of intangible assets (i.e., the largest is the $c_{F}-\widehat{c}_{F}$ difference), the more likely is that $D_{H}$ will insource the input under vertical FDI.

The second conclusion is that when the transfer of intangible assets is not effective, i.e., when $c_{F}=\widehat{c}_{F}$, vertical FDI has no impact at all on the MNE's input sourcing decision. That is, $D_{H}$ sources the input then from the same supplier with and without vertical FDI. This is so because, as we saw before, when trading is through two-part tariffs, the equilibrium wholesale prices are 
equal to the marginal cost - there is no double marginalization under both vertical FDI and no vertical FDI. This last observation comes in contrast with the established view in the literature that argues that through vertical FDI, the MNE's parent firm achieves an improvement in the (variable) terms at which it sources the input from abroad. ${ }^{16}$

The last conclusion is that vertical FDI can result in (more) sales of $U_{F}$ in country $F$. In particular, when the transfer of assets is effective, $D_{F}$ is more likely to start sourcing (a larger quantity of) the input domestically with than without vertical FDI. ${ }^{17}$

\section{Buy vs. Make, Sell and (not) Buy}

We turn now to the first stage of the game and explore whether and when vertical FDI arises in equilibrium.

In the absence of vertical FDI, the profits of $D_{H}$ accrue only from its own sales in its home country. In particular, $D_{H}$ 's equilibrium net profits are given by (2) after substituting into them the appropriate equilibrium terms of trade:

$$
\begin{aligned}
& \pi_{D_{H}}^{N}=\pi_{D_{H}}\left(w_{H H}^{N}, F_{H H}^{N}\right)=\left(p\left(q_{H}^{*}\left(C_{H F}\right)\right)-C_{H F}\right) q_{H}^{*}\left(C_{H F}\right) \text { if } c_{H} \leq c_{F}+t, \text { and } \\
& \pi_{D_{H}}^{N}=\pi_{D_{H}}\left(w_{H F}^{N}, F_{H F}^{N}\right)=\left(p\left(q_{H}^{*}\left(C_{H H}\right)\right)-C_{H H}\right) q_{H}^{*}\left(C_{H H}\right) \text { if } c_{H}>c_{F}+t .
\end{aligned}
$$

In the presence of vertical FDI, $D_{H}$ obtains profits not only from its own sales in country $H, \pi_{D_{H H}}^{V}$, but also from the sales of $U_{F}$ in country $F, \pi_{U_{F F}}^{V}$. Hence, under vertical FDI, $D_{H}$ 's total net profits are $\pi_{D_{H}}^{V}=\pi_{D_{H}}^{V}+F_{F F}^{V}-A$. The first two terms of $\pi_{D_{H}}^{V}$ are obtained after substituting the appropriate equilibrium terms of trade under vertical FDI. The third term, the acquisition price $A$, is determined in the following way: $D_{H}$ knows that $U_{F}$ will accept the acquisition offer if and only if $A$ is as high as the profits that $U_{F}$ would make if it rejected the offer. That is, if and only if $A$ is equal to $U_{F}$ 's profits under no vertical FDI. Taking this into account, $D_{H}$ optimally sets $A=F_{H F}^{N}+F_{F F}^{N}$.

Proposition 1 Vertical FDI arises in equilibrium if and only if $\widehat{c}_{F}<c_{F}$.

As Proposition 1 states, vertical FDI takes place whenever the transfer of intangible assets is effective. This holds independently of the presence or absence of intra-firm trade under vertical

\footnotetext{
${ }^{16}$ Note though that the same does not also hold for the fixed terms of trade (i.e., for $F_{H F}$ ), since the latter are by definition equal to zero under vertical FDI.

${ }^{17} \mathrm{~A}$ straightforward implication of the decrease in $U_{F}$ 's marginal cost from $c_{F}$ to $\widehat{c}_{F}$ is the respective decrease in $C_{F F}$. The latter can cause a switch in $D_{F}$ 's input supplier from $U_{H}$ to $U_{F}$ or it can lead to an increase in $q_{F}\left(C_{F F}\right)$.
} 
FDI. In other words, the home downstream firm has incentives to establish a foreign upstream affiliate even when it does not source the input from the latter. Why?

To answer the above, first consider the case in which the MNE makes, sells and buys the input, that is, the case which, according to Lemma 2, arises when $\widehat{c}_{F}-t<c_{H}<\widehat{c}_{F}+t$. In such a case, vertical FDI accompanied by the effective transfer of intangible assets gives rise to two effects. The first effect refers to the fact that vertical FDI results in (more) sales for $U_{F}$ in country $F$ (i.e., sales to $D_{F}$ ), and thus, in profits for $D_{H}$ from the foreign country. This implies that vertical FDI allows the MNE's parent firm to take advantage of its intangible assets in another country besides its home country. From now on, we will refer to this effect as the assets exploitation effect of vertical FDI. The second effect is the outsourcing terms effect, which refers to the fact that vertical FDI causes an improvement in the terms in which $D_{H}$ sources the input from the external domestic input supplier. This arises because the effective transfer of assets to $U_{F}$ improves $D_{H}$ 's outside option in its trading with $U_{H}$ - it improves its cross-threat.

Consider now the (make), buy and not sell case, which arises when $c_{H}<\widehat{c}_{F}-t$. Although in this case the foreign upstream firm makes no sales, and thus, no profits in either country, the home downstream firm still has incentives to acquire it as long as the transfer of assets is effective. Hence, there are incentives for vertical FDI even when the cross-country factor cost differences do not work in favor of vertical FDI. Why is that? Vertical FDI is now driven exclusively by the outsourcing terms effect. In other words, vertical FDI is motivated by the achievement of better input sourcing terms domestically alone.

When the MNE's parent firm sources the input from its upstream affiliate, that is, in the make, sell and not buy case (when $c_{H}>\widehat{c}+t$ ), the effective transfer of intangible assets clearly does not give rise to the outsourcing terms effect. It gives rise instead to the assets exploitation effect as well as to an additional effect, the insourcing terms effect. The latter refers to the improvement in the terms at which $D_{H}$ insources the input under vertical FDI. Interestingly, this improvement is not driven by the disappearance of the mark-up that an external upstream firm could set on the input price. It is driven instead by the effective transfer of intangible assets.

When the transfer of intangible assets is not effective $\left(\widehat{c}_{F}=c_{F}\right)$, all the above mentioned effects that work in favor of vertical FDI are absent; hence, the incentives for vertical FDI are also absent. This observation highlights the key role of the transfer of intangible assets in the vertical FDI decision. Importantly, this observation is in line with the empirical study of Atalay et al. (2014), which using data from multi-plant firms within the U.S., concludes that one of the primary purposes for vertical ownership is the facilitation of the efficient transfer of intangible 
inputs within the firms. It is also in line with the empirical study of Ramondo et al. (2016), which argues that the reason that U.S. MNEs own international segmented production chains might be the fact that the transfer of intangible goods, such as know-how and organizational capabilities, along the vertical production chain can be a source of comparative advantage in the production of vertically related goods abroad. We provide here a formal theoretical support to this view. Moreover, we complement this view by pointing out that an additional motive for vertical FDI, besides the exploitation of intangible assets abroad, could be the strengthening of the MNEs' parent firms cross-threats in their trading with the domestic input suppliers, which leads to improved terms of trade domestically.

\section{Trade Liberalization}

In this Section, we explore how trade liberalization, captured by a tariff reduction, can affect international trade and the incentives for vertical FDI. We resort here, as well as in the rest of our analysis, to the use of the standard linear inverse demand function, $p\left(q_{i}\right)=a-q_{i}$, with $a-c_{i}>t>0$. Moreover, we focus here on the case in which the transfer of assets is effective. Doing so, we find the following.

Proposition 2 (i) Trade liberalization has a positive impact on the volume of international trade if $t$ is ex ante below $\min \left\{\widehat{c}_{F}-c_{H}, c_{H}-\widehat{c}_{F}\right\}$ or if it drops ex post below it, and no impact otherwise.

(ii) Trade liberalization has a positive impact on the incentives for vertical FDI unless $\widehat{c}_{F}-$ $c_{H}<t<\min \left\{c_{F}-c_{H}, a-c_{H}+\widehat{c}_{F}-c_{F}\right\}$. In the latter case, its impact is negative.

Proposition 2(i) informs us that, as expected, trade liberalization can enhance the volume of input imports. This holds when the tariff is sufficiently low before the tariff reduction takes place as well as when it is not sufficiently low but it drops sufficiently. In the former case, there are imports even before trade liberalization and the latter, by reducing the trade cost, results in an increase in their volume. In the second case, there are no imports before trade liberalization and a drop of $t$ can trigger them: $D_{H}$ starts sourcing the input from its foreign affiliate $U_{F}$, and thus, intra-firm input trade appears. ${ }^{18}$

According to Proposition 2(ii), trade liberalization can also the incentives for vertical FDI. Why is that? When input production is more efficient in the foreign country, $U_{F}$ 's sales in

\footnotetext{
${ }^{18}$ These findings are in line with the empirical findings of Feinberg and Keane (2001) and Hanson et al. (2005) who find that a fall in trade costs results in an increase in the quantity of intermediate inputs that U.S. parent firms import from their foreign affiliates. They are also in line with Hayakawa and Matsura (2015) who find a positive impact of trade liberalization of Asian host countries on the incoming Japanese vertical FDI.
} 
country $F$ do not depend on $t$, and thus, a tariff reduction has no impact at all on the assets exploitation effect. Still, a tariff reduction reinforces then either the insourcing terms effect or the outsourcing terms effect, strengthening the incentives for vertical FDI. More specifically, when $D_{H}$ imports the input from $U_{F}$ under vertical FDI, the lower is $t$, the better are its insourcing terms. Similarly, when $D_{H}$ sources the input from $U_{H}$ under vertical FDI, the lower is $t$, the stronger is its cross-threat, and thus, the better are its outsourcing terms.

However, when the input production is less efficient in the foreign country, trade liberalization can, under certain circumstances, weaken the incentives for vertical FDI. This is so because although a tariff reduction continues to boost either the outsourcing terms effect or the insourcing terms effect, it can now diminish the assets exploitation effect. This holds whenever $D_{F}$ imports the input from $U_{H}$ only under no vertical FDI (i.e., when $\widehat{c}_{F}-c_{H}<t<c_{F}-c_{H}$ ). In such a case, a tariff reduction improves the outside option of $D_{F}$, which negatively affects $U_{F}$ 's profits, and in turn, $D_{H}$ 's profits under vertical FDI. In other words, in such a case, the lower is $t$, the stronger is the negative impact of trade liberalization on the assets exploitation effect, and in turn the less likely is that trade liberalization will reinforce the vertical FDI incentives.

According to the traditional international economics theory (see e.g., Markusen, 2002), trade liberalization, by weakening the "tariff-jumping" motive for FDI, should encourage international trade and discourage FDI. In contrast to this, we conclude that trade liberalization can enhance both FDI and international trade. Doing so, we provide an explanation for the extensive empirical evidence which demonstrate that over the last three decades, the increase in trade liberalization has been accompanied by an increase in both international trade and FDI. ${ }^{19}$

\section{Welfare Implications}

Next, we examine the welfare implications of vertical FDI for both the home and the foreign country. We focus on the case in which vertical FDI arises in equilibrium, i.e., $\widehat{c}_{F}<c_{F}$.

Proposition 3 (i) Vertical FDI has a positive impact on the consumers' surplus of the home country if $c_{H}>\widehat{c}_{F}+t$, and no impact otherwise.

(ii) Vertical FDI increases the total welfare of the home country if $c_{H}+t>c_{F}$. When $c_{H}+t<c_{F}$, there exist two threshold values, $t_{0}$ and $t_{1}$, such that vertical FDI reduces the total

\footnotetext{
${ }^{19}$ In fact, according to data from the WTO and the UNCTAD, between 1980 and 2008, world trade increased sevenfold and FDI almost thirtyfold, both outpacing the increase in world GDP in the same period. For alternative explanations for the positive impact of trade liberalization on FDI see e.g., Motta and Norman (1996), Bjorvatn (2004).
} 
welfare of the home country if either (a) $c_{H}<\widehat{c}_{F}<c_{F}$ and $t<t_{0}$ or (b) $\widehat{c}_{F}<c_{H}<c_{F}$ and $t<$ $\min \left\{t_{1}, c_{H}-\widehat{c}_{F}, c_{F}-c_{H}\right\}$, and increases it otherwise.

According to Proposition 3(i), vertical FDI can either have no effect on the consumers of the home country or it can be beneficial for them. The intuition is as follows. Recall that $D_{i}$ sources the input from the upstream firm from which it faces the lowest total marginal cost $C_{i k}$. When $D_{H}$ sources the input from $U_{H}$, vertical FDI does not affect $C_{i H}$. However, when it sources the input from $U_{F}$, vertical FDI decreases $C_{i F}$ by reducing $U_{F}$ 's marginal production cost from $c_{F}$ to $\widehat{c}_{F}$. In other words, vertical FDI has either no effect or a positive effect on $D_{H}$ 's efficiency. A straightforward implication of this is that $D_{H}$ 's output and, in turn, the home country's consumers' surplus under vertical FDI is either equal or larger than the respective one under no vertical FDI.

The home country's tariff revenues, similarly to its consumers' surplus, either increase or remain unchanged with vertical FDI. This is so because vertical FDI can either trigger $D_{H}$ 's imports from $U_{F}$, it can increase them, or it can leave them unchanged.

Regarding the home country's producers' surplus, we know from Proposition 1 that $D_{H}$ 's profits are higher with than without vertical FDI. The profits of $U_{H}$ though can be lower with vertical FDI under certain circumstances. In particular, when $c_{H}<c_{F}$ and $t$ is sufficiently low, $U_{H}$ sells the input to $D_{F}$ under no vertical FDI; as a result, when vertical FDI takes place, the competitiveness of its rival, $U_{F}$, increases, and thus, the profits of $U_{H}$ decrease either because (a) it ends up charging its customer $\left(D_{F}\right)$ a lower fixed fee or (b) because $D_{F}$ switches to sourcing the input from $U_{F}$. In case (a), the only (net) effect of vertical FDI on the home country's total welfare is the drop in the fixed fee that $U_{H}$ charges to $D_{H}$. In case (b), however, there is an additional gain for the home country because $D_{H}$ gets the profits that $U_{F}$ obtains in country $F$ by supplying the input to $D_{F}$. According to Proposition 3 , for sufficiently low values of $t, U_{H}$ 's losses dominate, rendering vertical FDI detrimental for the home country's welfare. ${ }^{20}$

Next, we examine whether vertical FDI is welfare-enhancing for the foreign country.

Proposition 4 (i) Vertical FDI has a positive impact on the consumers' surplus of the foreign country if $\widehat{c}_{F}<c_{H}+t$, and no impact otherwise.

(ii) Vertical FDI increases the total welfare of the foreign country if $c_{H}+t>c_{F}$. When $c_{H}+t<c_{F}$, there exists a threshold value, $t_{2}$, such that vertical FDI reduces the total welfare of the foreign country if (a) $c_{H}<\widehat{c}_{F}<c_{F}$ and $\max \left\{\widehat{c}_{F}-c_{H}, t_{2}\right\}<t<c_{F}-c_{H}$, as well as if

\footnotetext{
${ }^{20}$ The threshold values $t_{0}$ and $t_{1}$ as well as a detailed analysis of the welfare effects of vertical FDI in all possible scenarios can be found in the proof of Proposition 3, in the Appendix.
} 
(b) $\widehat{c}_{F}<c_{H}<c_{F}$ and $\max \left\{c_{H}-\widehat{c}_{F}, t_{2}\right\}<t<c_{F}-c_{H}$ or $(c) \widehat{c}_{F}<c_{H}<c_{F}$ and $t_{2}<t<$ $\min \left\{c_{F}-c_{H}, c_{H}-\widehat{c}_{F}\right\}$, and it increases it otherwise.

Vertical FDI can not hurt the consumers of the foreign country either. By resulting in a reduction in $U_{F}$ 's marginal cost, vertical FDI increases country $F$ 's efficiency. This efficiency gain materializes only when $U_{F}$ makes sales under vertical FDI (when $\widehat{c}_{F}<c_{H}+t$ ); hence, the consumers' surplus in the foreign country increases then with vertical FDI. Otherwise, vertical FDI does not affect the foreign consumers.

It is quite intuitive that in the absence of a tariff, vertical FDI can not be welfare-reducing for the foreign country. In particular, given that in equilibrium the inputs are always sold at marginal cost and $U_{F}$ is fully compensated under vertical FDI (through $A$ ), when $t=0$, a welfare loss can occur in country $F$ only through a decrease in its cost efficiency, which never takes place. Still, Proposition 4(ii) informs us that vertical FDI reduces the foreign country's total welfare whenever $t$ is not too low but it is lower than $c_{F}-c_{H}$. Why is that? The answer has to do with the negative impact that vertical FDI can have on the foreign country's tariff revenues. The latter occurs whenever vertical FDI alters $D_{F}$ 's input sourcing decision from offshoring, which generates tariff revenues in the foreign country, to domestic outsourcing, which eliminates the tariff revenues (e.g., when $\widehat{c}_{F}-c_{H}<t<c_{F}-c_{H}$ ).

Combining Propositions 3 and 4, we note that there exist cases in which vertical FDI reduces total welfare in one country and increases it in the other. For instance, setting $a=20, \widehat{c}_{F}=1$, $c_{H}=2$ and $c_{F}=6$, it is direct to see that when $t<0.69$, vertical FDI is welfare-reducing for the home country and welfare-enhancing for the foreign country; when instead $0.69<t<3.18$, vertical FDI increases welfare in both countries; when $3.18<t<4$, vertical FDI is welfareenhancing for the home country and welfare-reducing for the foreign country. Finally, when $4<t(<14)$, vertical FDI increases welfare in both countries.

In light of the potentially different implications of vertical FDI on the welfare of the two countries, one might wonder about its impact on their joint total welfare.

Proposition 5 (i) Vertical FDI has a positive impact on the joint total welfare of the two countries if $c_{H}+t>c_{F}$.

(ii) When $c_{H}+t<c_{F}$, there exists a threshold value, $t_{3}$, such that vertical FDI has a negative impact on the joint total welfare of the two countries if $\widehat{c}_{F}-c_{H}<t<\min \left\{t_{3}, c_{F}-c_{H}\right\}$, no impact if $t<\widehat{c}_{F}-c_{H}$, and a positive impact otherwise.

When the transfer of intangible assets is effective, vertical FDI gives rise to an efficiency gain. On the basis of this, we would expect that vertical FDI increases the joint total welfare of 
the two countries. However, this is not always the case. This result, which is counterintuitive at first sight, is driven by the fact that under certain circumstances, vertical FDI also causes an inefficiency. In particular, consider the case in which the home input supplier is more efficient that the foreign one even after vertical FDI takes place $\left(c_{H}<\widehat{c}_{F}\right)$. In such a case, $D_{H}$ sources the input domestically both with and without vertical FDI; hence, the total surplus generated in the home country does not change with vertical FDI. Suppose also that $\widehat{c}_{F}-c_{H}<t<c_{F}-c_{H}$, so that when vertical FDI materializes, $D_{F}$ changes its input supplier from $U_{H}$ to $U_{F}$. In this scenario, $D_{F}$, due to vertical FDI, ends up using an input which is produced at a higher cost. The (socially) inefficient behavior of $D_{F}$ arises from the existence of the tariff. As Proposition 5 states, when $t$ is sufficiently high within this region $\left(\widehat{c}_{F}-c_{H}<t<\min \left\{t_{3}, c_{F}-c_{H}\right\}\right)$, the (in)efficiency effect dominates the efficiency gain resulting in the undesirability of vertical FDI from a joint total welfare perspective.

Interestingly, for a particular set of parameters, vertical FDI has no effect on the joint welfare of the two countries. This occurs when $c_{H}+t<\widehat{c}_{F}$, i.e., when both $D_{H}$ and $D_{F}$ source the input from $U_{H}$ with and without vertical FDI. In this case, $U_{F}$ makes no sales, and thus, the marginal cost reduction generated by vertical FDI cannot be exploited; hence, although vertical FDI changes the way in which the total surplus is shared, the size of the total surplus remains unchanged.

In light of the above, we can draw a number of policy conclusions regarding the treatment of vertical cross-border M\&As. Our results suggest that if the national competition authorities of the concerned countries use consumers' surplus as their standard in the evaluation of M\&As, then they should both approve a vertical cross-border acquisition as the one considered here. However, if a total welfare standard is used (this is the case in some countries, e.g., Canada, Australia), then conflicting interests can arise that could lead to the rejection of such an acquisition in one country and its approval in the other. In the latter case, the existence of a supranational competition policy authority (e.g., the European Commission) could potentially resolve the problem by evaluating the acquisition using its overall impact on the two countries as its criterion. ${ }^{21,22}$

\footnotetext{
${ }^{21} \mathrm{~A}$ few papers that consider horizontal M$\&$ As in open economies, and not vertical cross-border M\&As, also identify potential conflicts that could arise between the national competition authoririties of different countries (e.g., Keith and Ries, 1997; Breinlich et al., 2016).

${ }^{22}$ As Horn and Levinshon (2001, p. 244) state: "International organisations traditionally concerned with trade policies have also turned their attention to competition policies [...] The European Union has gone even further, suggesting an international agreement in competition policies. The EU has also in practice sought to solve the problem of often conflicting competition policies in the context of a unified European market through supranational competition policies."
} 


\section{Extensions}

\subsection{Domestic Vertical Acquisition}

In our main model, we have assumed that the home downstream firm considers acquiring the foreign upstream firm. One might though wonder whether it would prefer to acquire instead the domestic upstream firm. Next, we explore this issue.

We extend now our model and assume that in the first stage of the game, $D_{H}$ chooses among acquiring $U_{H}$, acquiring $U_{F}$, and no acquisition at all. In addition, we assume that $D_{H}$ transfers its intangible assets to $U_{H}$ when the latter accepts the acquisition offer, $A_{H}$. This transfer can lead to a reduction in $U_{H}$ 's local marginal cost from $c_{H}$ to $\widehat{c}_{H}$. We focus on the case in which $c_{H}-\widehat{c}_{H}=c_{F}-\widehat{c}_{F}>0$.

$>$ From Proposition 1, we know that when the transfer of assets is effective, $D_{H}$ is better off with than without vertical cross-border acquisition. Given this, in what follows we only need to determine $D_{H}$ 's preferred acquisition target, i.e., to compare its profits with cross-border acquisition and domestic acquisition.

Proposition 6 The home downstream firm prefers vertical cross-border acquisition over vertical domestic acquisition if $c_{H}+t>c_{F}$. Otherwise, it prefers vertical domestic acquisition.

Proposition 6 informs us that the home downstream firm prefers acquiring $U_{F}$ rather than $U_{H}$ when the former is more efficient as well as when it is less efficient and the tariff is sufficiently high. Thus, under certain conditions, a cross-border acquisition is preferred over a domestic acquisition. Why is that?

Consider first the case in which $U_{F}$ is more efficient than $U_{H}$. Although in such a case, the acquisition of $U_{F}$ is more expensive than that of $U_{H}, D_{H}$ prefers to acquire the former. This occurs because the assets exploitation effect is stronger then. In particular, under domestic acquisition, $D_{F}$ either sources the input domestically, and thus, the assets exploitation effect is absent, or it imports a lower quantity than the one that it sources from $U_{F}$ under crossborder acquisition (since $c_{F}<c_{H}$ implies that $\widehat{c}_{F}<\widehat{c}_{H}+t$ also holds). In addition, this can also occur because the insourcing terms effect is stronger under vertical cross-border acquisition when $c_{F}+t<c_{H}$, and thus, when the cost that $D_{H}$ faces when it sources the input from its upstream affiliate is lower when the latter is located abroad.

Consider now the case in which $U_{F}$ is less efficient than $U_{H}$ and the tariff is sufficiently high. The insourcing terms effect is now always in favor of domestic acquisition. This is so because $c_{H}<c_{F}$ implies that $c_{F}+t<c_{H}$ always holds now. Still, cross-border acquisition is preferred 
due again to the intensity of the assets exploitation effect which is stronger under cross-border acquisition in this case too for the above mentioned reasons.

We can relate the result in Proposition 6 with our previous conclusion that vertical FDI can arise in equilibrium even when the MNE's parent firm does not source the input from its foreign affiliate. In particular, Proposition 6 implies that this conclusion continues to hold even when the home downstream firm has the possibility to choose vertical domestic acquisition instead, at least as long as $c_{H}+t>c_{F} \cdot{ }^{23}$

\subsection{Linear Contracts}

Up to now we have performed our analysis assuming that input trading takes place through two-part tariff contracts. Here, we examine the robustness of our main findings when vertical trading takes place instead through wholesale price contracts, i.e., through contracts which include only $w_{i k}$. In order to guarantee that the upstream cost asymmetry is not too large, and in particular, that the efficient upstream supplier cannot behave as a monopolist, we assume now that $a>2 c_{j}-c_{i}$ when $c_{i}<c_{j}$. We allow for $\widehat{c}_{F} \leq c_{F}$.

Under no vertical FDI, the Nash equilibrium of the wholesale price game involves the less efficient upstream firm offering to $D_{i}$ a wholesale price equal to its own marginal cost and the more efficient upstream firm offering a limit wholesale price which is above its own marginal cost and just below its rival's cost. ${ }^{24}$ Clearly, the latter becomes $D_{i}$ 's input supplier. It follows that under wholesale price contracts, in contrast to what happens under two-part tariffs, $D_{i}$ 's input supplier sets a positive mark-up on the wholesale price; double marginalization is present.

Under vertical FDI, $D_{H}$ can insource the input at marginal cost $C_{H F}=\widehat{c}_{F}+t$ from $U_{F}$. Because of this, the offer made by $U_{H}$ to $D_{H}$, in line with the above, is $w_{i H}^{V}=c_{H}$ if $C_{i H}>C_{i F}$ and $w_{i H}^{V}=c_{F}$ if $C_{i H}<C_{i F}$ and $D_{H}$ chooses respectively insourcing and outsourcing.

Taking the above into account, we find that vertical FDI arises in equilibrium not only when the transfer of intangible assets is effective, but also when it is not and $t<c_{H}-c_{F}$. In the former case, if the tariff is not sufficiently high, the motive for vertical FDI is again the insourcing terms effect along with the assets exploitation effect. If instead the tariff is sufficiently high, the motive for vertical FDI is the outsourcing terms effect alone or along with the assets exploitation effect.

When $\widehat{c}_{F}=c_{F}$ and $t<c_{H}-c_{F}, D_{H}$ sources the input from $U_{F}$ both with and without vertical FDI. Clearly, in such a case, vertical FDI is motivated by neither of the effects identified

\footnotetext{
${ }^{23}$ It is easy to check that the condition $c_{H}+t>c_{F}$ includes the make, sell and buy case where, after the crossborder acquistion takes place, both downstream firms choose to source the input domestically. In particular, this would be the case if e.g., $c_{F}<c_{H}$ and $c_{F}+t>c_{H}$.

${ }^{24}$ For more on this see Mathewson and Winter (1987).
} 
in our main analysis. It is motivated instead by the elimination of the double marginalization that takes places when vertical FDI materializes. In other words, in this case the motivation for vertical FDI is in line with the conventional wisdom.

\section{Concluding Remarks}

We have explored the incentives for vertical FDI along with its implications in a partial equilibrium model with two countries and two stages of production. We have focused on backward vertical FDI that takes place through a cross-border acquisition. We have allowed for the transfer of intangible assets among the MNE's vertically related production plants, without presuming that there is also transfer of products (i.e., intra-firm trade) among them.

We have shown that the motives for vertical FDI are more complex than conventionally assumed. A MNE does not always undertake vertical FDI in order to secure better input sourcing terms from a foreign country with more efficient input production. A MNE might undertake vertical FDI even when a foreign downstream firm and not its parent firm sources the input from its own foreign upstream affiliate. That is, there are cases in which the MNE makes, sells and buys the input. In such cases, as long as there is an effective transfer of intangible assets between the MNE's parent firm and affiliate, the MNE engages in FDI for two reasons. The first reason is the exploitation of its intangible assets in another country besides its home country. The second reason is the improvement in its cross-threat in the trading with the domestic input supplier, and thus, the achievement of better input sourcing terms domestically. In fact, we find cases in which vertical FDI can be motivated by the second reason alone.

We have also shown that trade liberalization can enhance not only the volume of international trade in intermediate products but also the incentives for vertical FDI. This occurs through the enhancement that it causes in the input sourcing terms of the MNE's parent firm. Finally, we have shown that vertical FDI is welfare increasing for both the home and the foreign country as long as the latter is more efficient in input production. Otherwise, the welfare implications of vertical FDI can be negative as well as they can differ among the two countries; vertical FDI can be welfare-enhancing for one country and welfare-detrimental for the other.

Summing up, we have performed an in depth analysis of the incentives for vertical FDI. We have provided a theoretical explanation for the recent empirical findings that report many instances in which there is no intra-firm trade within vertically integrated MNEs as well as for the empirically documented positive impact of trade liberalization on both international trade and FDI. Finally, we have pointed out that a number of issues arise regarding the treatment of 
cross-border vertical mergers and acquisitions by the competition policy authorities of different countries and the potential need for coordination among them on an international level.

In future work, we plan to enrich our analysis by considering the role of downstream competition as well as by examining the interactions and conflicts that can arise in the simultaneous optimal design of trade policy, competition policy and FDI attracting policy. ${ }^{25}$

\section{Appendix}

Proof of Lemma 1: We start by determining $D_{H}$ 's input sourcing decision. If $t>c_{H}-c_{F}$, then given that $w_{H H}^{N}=c_{H}$ and $w_{H F}^{N}=c_{F}$, we have $C_{H H}<C_{H F}$. Since the maximized stand-alone joint profits of the $\left(U_{k}, D_{i}\right)$ pair decrease with $C_{i k}$, it follows that $\pi_{U_{H} D_{H}}\left(C_{H H}\right)>$ $\pi_{U_{F} D_{H}}\left(C_{H F}\right)$. The latter implies that in equilibrium $F_{H H}^{N}=\pi_{U_{H} D_{H}}\left(C_{H H}\right)-\pi_{U_{F} D_{H}}\left(C_{H F}\right)$ and $F_{H F}^{N}=0$. Substituting the equilibrium terms of trade into (2), we note that $\pi_{D_{H}}\left(C_{H H}, F_{H H}^{N}\right)>$ $\pi_{D_{H}}\left(C_{H F}, F_{H F}^{N}\right)$. If instead $t<c_{H}-c_{F}$, then given that $w_{H H}^{N}=c_{H}$ and $w_{H F}^{N}=c_{F}$, we have $C_{H H}<C_{H F}$. Following the same reasoning as above, we obtain: $F_{H H}^{N}=0$ and $F_{H F}^{N}=$ $\pi_{U_{F} D_{H}}\left(C_{H F}\right)-\pi_{U_{H} D_{H}}\left(C_{H H}\right)$. Hence, $\pi_{D_{H}}\left(C_{H H}, F_{H H}^{N}\right)<\pi_{D_{H}}\left(C_{H F}, F_{H F}^{N}\right)$. It follows that $D_{H}$ decides to source the input from $U_{H}$ if $t>c_{H}-c_{F}$ and from $U_{F}$ otherwise.

We turn now to $D_{F}$ 's input sourcing decision. Since $w_{F H}^{N}=c_{H}$ and $w_{F F}^{N}=c_{F}$, it follows that $C_{F H}=c_{H}+t$ and $C_{F F}=c_{F}$. Given this, if $t>c_{F}-c_{H}$, then $C_{F H}>C_{F F}$, which implies that the maximized stand-alone joint profits of the $\left(U_{F}, D_{F}\right)$ pair are higher than those of the $\left(U_{H}, D_{F}\right)$ pair. Therefore, $F_{F H}^{N}=0$ and $F_{F F}^{N}=\pi_{U_{F} D_{F}}\left(C_{F F}\right)-\pi_{U_{H} D_{F}}\left(C_{F H}\right)$, and in turn, $\pi_{D_{F}}\left(C_{F H}, F_{F H}\right)<\pi_{D_{F}}\left(C_{F F}, F_{F F}\right)$. If instead $t<c_{F}-c_{H}$, then $C_{F H}<C_{F F}$. Thus, in equilibrium $F_{F H}^{N}=\pi_{U_{H} D_{F}}\left(C_{F H}\right)-\pi_{U_{F} D_{F}}\left(C_{F F}\right)$ and $F_{F F}^{N}=0$ and, in turn, $\pi_{D_{F}}\left(C_{F H}, F_{F H}^{N}\right)>$ $\pi_{D_{F}}\left(C_{F F}, F_{F F}^{N}\right)$. It follows that $D_{F}$ optimally chooses outsourcing if $t>c_{F}-c_{H}$ and offshoring otherwise.

Proof of Lemma 2: (i) Under vertical FDI, $D_{H}$ can obtain the input from $U_{F}$ at $\widehat{c}_{F}+t$ or from $U_{H}$ at $w_{H H}^{V}=c_{H}$. In other words, under vertical FDI, $C_{H H}=c_{H}$ and $C_{H F}=\widehat{c}_{F}+t$. Therefore, if $t>c_{H}-\widehat{c}_{F}$, then $C_{H H}<C_{H F}$, which implies that $\pi_{U_{H} D_{H}}\left(C_{H H}\right)>\pi_{U_{F} D_{H}}\left(C_{H F}\right)$. As a consequence, $F_{H H}^{V}=\pi_{U_{H} D_{H}}\left(C_{H H}\right)-\pi_{U_{F} D_{H}}\left(C_{H F}\right)$, and, in turn, $\pi_{D_{H}}\left(C_{H H}, F_{H H}^{V}\right)>$ $\pi_{D_{H}}\left(C_{H F}, F_{H F}^{V}\right)$. If instead $t<c_{H}-\widehat{c}_{F}$, then $C_{H H}>C_{H F}$. Therefore, $F_{H H}^{V}=0$ and, in turn, $\pi_{D_{H}}\left(C_{H H}, F_{H H}^{V}\right)<\pi_{D_{H}}\left(C_{H F}, F_{H F}^{V}\right)$. It follows that $D_{H}$ optimally chooses outsourcing if

\footnotetext{
${ }^{25}$ The inclusion of downstream competition could give rise to serious complications regarding the existence of equilibrium and the beliefs formed by firms when rival upstream firms deal with the same competing downstream firms through non-linear contracts. For more on this, see two reviews of the literature on vertically related markets by Inderst (2010) and Miklós-Thal et al. (2010).
} 
$t>c_{H}-\widehat{c}_{F}$ and insourcing otherwise.

(ii) Since $w_{F H}^{V}=c_{H}$ and $w_{F F}^{V}=c_{F}$, it follows that $C_{F H}=c_{H}+t$ and $C_{F F}=\widehat{c}_{F}$. Given this, if $t>\widehat{c}_{F}-c_{H}$, then $C_{F H}>C_{F F}$, and, in turn, $U_{H}$ and $U_{F}$ optimally set $F_{F H}^{V}=0$ and $F_{F F}^{V}=\pi_{U_{F} D_{F}}\left(C_{F F}\right)-\pi_{U_{H} D_{F}}\left(C_{F H}\right)$. A straightforward implication is that $\pi_{U_{H} D_{F}}\left(C_{F H}\right)<$ $\pi_{U_{F} D_{F}}\left(C_{F F}\right)$. If, instead, $t<\widehat{c}_{F}-c_{H}$, then $C_{F H}<C_{F F}$; hence, the optimal fixed fees are $F_{F H}^{V}=\pi_{U_{H} D_{F}}\left(C_{F H}\right)-\pi_{U_{F} D_{F}}\left(C_{F F}\right)$ and $F_{F F}^{V}=0$. It follows from this that now $\pi_{U_{H} D_{F}}\left(C_{F H}\right)>$ $\pi_{U_{F} D_{F}}\left(C_{F F}\right)$. Thus, $D_{F}$ resorts to offshoring if $t<\widehat{c}_{F}-c_{H}$ and to outsourcing otherwise.

Proof of Proposition 1: We start with the case in which $c_{H}>c_{F}$. Clearly, in this case, $D_{F}$ always obtains the input from $U_{F}$. We distinguish among the following sub-cases:

(i) If $t>c_{H}-\widehat{c}_{F}$, then $C_{H H}<C_{H F}$ and thus $D_{H}$ will not obtain the input from $U_{F}$ both with and without vertical FDI. In this case, the resulting total net profits of $D_{H}$ are given by (4) under no vertical FDI and by:

$$
\begin{aligned}
\pi_{D_{H}}^{V}= & \left(p\left(q_{H}^{*}\left(\widehat{C}_{H F}\right)\right)-\widehat{C}_{H F}\right) q_{H}^{*}\left(\widehat{C}_{H F}\right)+\left(p\left(q_{F}^{*}\left(\widehat{C}_{F F}\right)\right)-\widehat{C}_{F F}\right) q_{F}^{*}\left(\widehat{C}_{F F}\right) \\
& -\left(p\left(q_{F}^{*}\left(C_{F F}\right)\right)-C_{F F}\right) q_{F}^{*}\left(C_{F F}\right),
\end{aligned}
$$

under vertical FDI, with $\widehat{C}_{H F} \equiv \widehat{c}_{F}+t$ and $\widehat{C}_{F F} \equiv \widehat{c}_{F}$. Calculating their difference, we have:

$$
\begin{aligned}
\pi_{D_{H}}^{V}-\pi_{D_{H}}^{N}= & \left(p\left(q_{H}^{*}\left(\widehat{C}_{H F}\right)\right)-\widehat{C}_{H F}\right) q_{H}^{*}\left(\widehat{C}_{H F}\right)-\left(p\left(q_{H}^{*}\left(C_{H F}\right)\right)-C_{H F}\right) q_{H}^{*}\left(C_{H F}\right) \\
& +\left(p\left(q_{F}^{*}\left(\widehat{C}_{F F}\right)\right)-\widehat{C}_{F F}\right) q_{F}^{*}\left(\widehat{C}_{F F}\right)-\left(p\left(q_{F}^{*}\left(C_{F F}\right)\right)-C_{F F}\right) q_{F}^{*}\left(C_{F F}\right) .
\end{aligned}
$$

It can be easily observed that (8) is equal to zero if $\widehat{c}_{F}=c_{F}$ while it is positive if $\widehat{c}_{F}<c_{F}$.

(ii) If $c_{H}-\widehat{c}_{F}>t>c_{H}-c_{F}$, then $D_{H}$ sources the input from $U_{F}$ only under vertical FDI. In this case, $D_{H}$ 's total profits without vertical FDI are given by (4), while its profits with vertical FDI are given by (6) from above. Therefore, their difference coincides with (8); hence, in this case, $D_{H}$ always has incentives to undertake vertical FDI since the condition $c_{H}-\widehat{c}_{F}>t>c_{H}-c_{F}$ is satisfied only if $\widehat{c}_{F}<c_{F}$.

(iii) If $c_{H}-c_{F}>t$, then $D_{H}$ sources the input from $U_{F}$ both with and without vertical FDI. Its profits under no vertical FDI are given now by (5). Its profits instead under vertical FDI are 
given by:

$$
\begin{aligned}
\pi_{D_{H}}^{V}= & \left(p\left(q_{H}^{*}\left(\widehat{C}_{H F}\right)\right)-\widehat{C}_{H F}\right) q_{H}^{*}\left(\widehat{C}_{H F}\right)+\left(p\left(q_{F}^{*}\left(\widehat{C}_{F F}\right)\right)-\widehat{C}_{F F}\right) q_{F}^{*}\left(\widehat{C}_{F F}\right) \\
& -\left(p\left(q_{H}^{*}\left(C_{H F}\right)\right)-C_{H F}\right) q_{H}^{*}\left(C_{H F}\right)+\left(p\left(q_{H}^{*}\left(C_{H H}\right)\right)-C_{H H}\right) q_{H}^{*}\left(C_{H H}\right) \\
& -\left(p\left(q_{F}^{*}\left(C_{F F}\right)\right)-C_{F F}\right) q_{F}^{*}\left(C_{F F}\right) .
\end{aligned}
$$

The difference between (9) and (5) coincides with (8). Therefore, as in (i) and (ii), $D_{H}$ undertakes vertical FDI when the transfer of its intangible assets is effective.

We move now to the case in which $c_{H}<c_{F}$. In this case, $D_{H}$ always source the input from $U_{H}$ under no vertical FDI, and thus, its profits under no vertical FDI are given by (4). We distinguish among the following sub-cases:

(i) $c_{F} \geq \widehat{c}_{F}>c_{H}$ and $t>c_{F}-c_{H}$ : In this case, $D_{H}$ sources the input from $U_{H}$ and $D_{F}$ sources the input from $U_{F}$ under both vertical FDI and no vertical FDI. This implies that $U_{F}$ makes positive profits from country $F$ both with and without vertical FDI. Making the appropriate substitutions, we observe that the total profits of $D_{H}$ under vertical FDI are given by (6) from above. Therefore, their difference between $D_{H}$ 's profits with vertical FDI (6) and without vertical FDI (4) is given again by (7). Hence, vertical FDI arises in equilibrium if and only if $\widehat{c}_{F}<c_{F}$.

(ii) $c_{F}>\widehat{c}_{F}>c_{H}$ and $c_{F}-c_{H}>t>\widehat{c}_{F}-c_{H}$ : In this case, $D_{H}$ sources the input from $U_{H}$ under both vertical FDI and no vertical FDI, while $D_{F}$ sources the input from $U_{H}$ only under no vertical FDI, and thus, $A^{*}=0$. Substituting the appropriate equilibrium contract terms, we obtain $D_{H}$ 's profits under vertical FDI and subtracting (4) from them, we have:

$$
\begin{aligned}
\pi_{D_{H}}^{V}-\pi_{D_{H}}^{N}= & \left(p\left(q_{H}^{*}\left(\widehat{C}_{H F}\right)\right)-\widehat{C}_{H F}\right) q_{H}^{*}\left(\widehat{C}_{H F}\right)-\left(p\left(q_{H}^{*}\left(C_{H F}\right)\right)-C_{H F}\right) q_{H}^{*}\left(C_{H F}\right) \\
& +\left(p\left(q_{F}^{*}\left(\widehat{C}_{F F}\right)\right)-\widehat{C}_{F F}\right) q_{F}^{*}\left(\widehat{C}_{F F}\right)-\left(p\left(q_{F}^{*}\left(C_{F H}\right)\right)-C_{F H}\right) q_{F}^{*}\left(C_{F H}\right) .
\end{aligned}
$$

This difference $\pi_{D_{H}}^{V}-\pi_{D_{H}}^{N}$ is now always positive since $c_{F}>\widehat{c}_{F}>c_{H}$ and $t>\widehat{c}_{F}-c_{H}$.

(iii) $c_{F} \geq \widehat{c}_{F}>c_{H}$ and $t<\widehat{c}_{F}-c_{H}$ : In this case, $D_{H}$ sources the input from $U_{H}$ under both vertical FDI and no vertical FDI, while $D_{F}$ imports the input both with and without vertical FDI. Therefore, $A^{*}=0$ and $D_{H}$ makes profits only from sales in country $H$. Its profits under vertical FDI are thus given by $\pi_{D_{H}}^{V}=\left(p\left(q_{H}^{*}\left(\widehat{C}_{H F}\right)\right)-\widehat{C}_{H F}\right) q_{H}^{*}\left(\widehat{C}_{H F}\right)$. Hence, the difference 
between them and (4) is:

$$
\pi_{D_{H}}^{V}-\pi_{D_{H}}^{N}=\left(p\left(q_{H}^{*}\left(\widehat{C}_{H F}\right)\right)-\widehat{C}_{H F}\right) q_{H}^{*}\left(\widehat{C}_{H F}\right)-\left(p\left(q_{H}^{*}\left(C_{H F}\right)\right)-C_{H F}\right) q_{H}^{*}\left(C_{H F}\right),
$$

which is positive if and only if $\widehat{c}_{F}<c_{F}$.

(iv) $c_{F}>c_{H}>\widehat{c}_{F}, t>c_{F}-c_{H}$ and $t>c_{H}-\widehat{c}_{F}$ : In this case, none of the downstream firms ever imports the input. The resulting profits of the home retailer $D_{H}$ under vertical FDI are given by (6). Therefore, the difference in $D_{H}$ 's profits with vertical FDI (6) and without vertical FDI (4) is given again by (7). Since $\widehat{c}_{F}<c_{F},(7)$ is positive.

(v) $c_{F}>c_{H}>\widehat{c}_{F}, t<c_{F}-c_{H}$ and $t>c_{H}-\widehat{c}_{F}$ : In this case, $D_{H}$ never imports the input and $D_{F}$ imports it only under no vertical FDI. Therefore, in this case, $A^{*}=0$ and the profits of $D_{H}$ under vertical FDI are given by (9). Therefore, the difference in $D_{H}$ 's profits with vertical FDI (9) and without vertical FDI (4) is given by (10). This difference is positive since in this case $\widehat{c}_{F}<c_{F}$ holds.

(vi) $c_{F}>c_{H}>\widehat{c}_{F}, t>c_{F}-c_{H}$ and $t<c_{H}-\widehat{c}_{F}$ : In this case, $D_{H}$ imports the input only under vertical FDI and $D_{F}$ never imports the input. Therefore, in this case the profits of $D_{H}$ under vertical FDI are given by $(6)$, and the difference in $D_{H}$ 's profits with vertical FDI (6) and without vertical FDI (4) is given by (7). This difference is positive since $\widehat{c}_{F}<c_{F}$.

(vii) $c_{F}>c_{H}>\widehat{c}_{F}, t<c_{F}-c_{H}$ and $t<c_{H}-\widehat{c}_{F}$ : In this case, $D_{F}$ imports the input only under no vertical FDI and $D_{H}$ imports it only under vertical FDI. Therefore, in this case, $A^{*}=0$ and the profits of $D_{H}$ under vertical FDI are given by (9). Therefore, the difference in $D_{H}$ 's profits with vertical FDI (9) and without vertical FDI (4) is given by (10). This difference is positive again since in this case $\widehat{c}_{F}<c_{F}$ and $c_{H}+t>\widehat{c}_{F}$ too.

\section{Proof of Proposition 2}

(i) We need to distinguish between case (a) $\widehat{c}_{F}<c_{F}<c_{H}$, case (b) $\widehat{c}_{F}<c_{H}<c_{F}$ and case (c) $c_{H}<\widehat{c}_{F}<c_{F}$. We know from Proposition 1 that, in all these cases, there is vertical FDI in equilibrium.

Case (a): We know from Lemmas 1 and 2 that $D_{F}$, independently of the level of $t$, does not import the input. Therefore, a decrease in $t$ will have no impact on its imports. On the other hand, $D_{H}$ imports the input if and only if $t<c_{H}-\widehat{c}_{F}$. When $D_{H}$ imports the input,

its quantity, and thus, the quantity of the imported input is: $q_{H}=\frac{a-\left(\widehat{c}_{F}+t\right)}{2}$. Therefore, in this case, a decrease in $t$ from a level above $c_{H}-\widehat{c}_{F}$ to a level below $c_{H}-\widehat{c}_{F}$ will trigger imports. Moreover, when $t$ is initially below $c_{H}-\widehat{c}_{F}$, a decrease in $t$ will result in an increase in the 
quantity of the imported input.

Case (b): We know from Lemma 2 that $D_{F}$ imports the input only when $c_{H}<\widehat{c}_{F}$ and $t<\widehat{c}_{F}-c_{H}$. These conditions do not hold in this case (notice that the second condition would be satisfied only for sufficiently negative values of $t$ ), implying that $D_{F}$ does not import the input and that a decrease in $t$ will not trigger its imports in this case. At the same time, we know that under vertical FDI, $D_{H}$ imports the input only when $c_{H}>\widehat{c}_{F}$ and $t<c_{H}-\widehat{c}_{F}$. The first condition holds in this case. When the second condition also holds, i.e., if $t<c_{H}-\widehat{c}_{F}$, $D_{H}$ imports the input and the quantity of the imported input is: $q_{H}=\frac{a-\left(\widehat{c}_{F}+t\right)}{2}$. Therefore, a decrease in $t$ from above $c_{H}-\widehat{c}_{F}$ to below $c_{H}-\widehat{c}_{F}$ will trigger imports in this case. Moreover, when in this case $t$ is initially below $c_{H}-\widehat{c}_{F}$, a decrease in $t$ will result in an increase in the quantity of the imported input.

Case (c): We know that $D_{H}$ will not import the input in this case. At the same time, we also know that in this case, $D_{F}$ will import the input if and only if $t<\widehat{c}_{F}-c_{H}$. When $D_{F}$ imports the input and the quantity of the imported input is: $q_{F}=\frac{a-\left(c_{H}+t\right)}{2}$. Therefore, when $t$ is initially below $\widehat{c}_{F}-c_{H}$, a decrease in $t$ will result into an increase in the quantity of the imported input.

(ii) We need to distinguish between case (a) $c_{H}>c_{F}$ and case (b) $c_{H}<c_{F}$.

Case (a): We know from the proof of Proposition 1 that the difference $\pi_{D_{H}}^{V}-\pi_{D_{H}}^{N}$ is given by (7), which for the linear demand case corresponds to:

$$
\pi_{D_{H}}^{V}-\pi_{D_{H}}^{N}=\frac{\left(a-\widehat{c}_{F}-t\right)^{2}}{4}-\frac{\left(a-c_{F}-t\right)^{2}}{4}+\frac{\left(a-\widehat{c}_{F}\right)^{2}}{4}-\frac{\left(a-c_{F}\right)^{2}}{4}
$$

Differentiating (12) in terms of $t$ we find:

$$
\frac{\partial\left(\pi_{D_{H}}^{V}-\pi_{D_{H}}^{N}\right)}{\partial t}=\frac{\widehat{c}_{F}-c_{F}}{2}
$$

Clearly, given that $\widehat{c}_{F}<c_{F}$, (13) is negative. Thus, a decrease in $t$, leads to an increase in $\pi_{D_{H}}^{V}-\pi_{D_{H}}^{N}$; hence, the lower is $t$, the stronger are the incentives for vertical FDI.

Case (b): From the proof of Proposition 1, we know that if $c_{F}>\widehat{c}_{F}>c_{H}$ and $t>c_{F}-c_{H}$ as well as when $c_{F}>c_{H}>\widehat{c}_{F}$ and $t>c_{F}-c_{H}$, then $\pi_{D_{H}}^{V}-\pi_{D_{H}}^{N}$ is given by (7) which corresponds to (12) in the linear demand case. Differentiating (12) in terms of $t$, we find (13), and thus, we conclude that $t$ has a positive impact on $\pi_{D_{H}}^{V}-\pi_{D_{H}}^{N}$. From the proof of Proposition 1, we also know that if $c_{F}>\widehat{c}_{F}>c_{H}$ and $t<c_{F}-c_{H}$, then $\pi_{D_{H}}^{V}-\pi_{D_{H}}^{N}$ is given by (10) when $t>\widehat{c}_{F}-c_{H}$ and by (11) when $t<\widehat{c}_{F}-c_{H}$, which for the linear demand case correspond respectively to: 


$$
\begin{gathered}
\pi_{D_{H}}^{V}-\pi_{D_{H}}^{N}=\frac{\left(a-\widehat{c}_{F}-t\right)^{2}}{4}-\frac{\left(a-c_{F}-t\right)^{2}}{4}+\frac{\left(a-\widehat{c}_{F}\right)^{2}}{4}-\frac{\left(a-c_{H}-t\right)^{2}}{4} ; \\
\pi_{D_{H}}^{V}-\pi_{D_{H}}^{N}=\frac{\left(a-\widehat{c}_{F}-t\right)^{2}}{4}-\frac{\left(a-c_{F}-t\right)^{2}}{4} .
\end{gathered}
$$

Differentiating (15) in terms of $t$, we obtain (13), which is negative. Therefore, if $c_{F}>\widehat{c}_{F}>c_{H}$ and $t<\widehat{c}_{F}-c_{H}$, a decrease in $t$ has a positive impact on $\pi_{D_{H}}^{V}-\pi_{D_{H}}^{N}$. Differentiating though (14) in terms of $t$ we obtain:

$$
\frac{\partial\left(\pi_{D_{H}}^{V}-\pi_{D_{H}}^{N}\right)}{\partial t}=\frac{\widehat{c}_{F}-c_{F}+a-c_{H}-t}{2}
$$

Expression (16) is positive if and only if $t<a-c_{H}+\widehat{c}_{F}-c_{F}$. Therefore, in this case, a decrease in $t$ has a positive impact on $\pi_{D_{H}}^{V}-\pi_{D_{H}}^{N}$ when either $t>a-c_{H}+\widehat{c}_{F}-c_{F}$ or $t<\widehat{c}_{F}-c_{H}$. Otherwise, it has a negative impact.

Finally, if $c_{F}>c_{H}>\widehat{c}_{F}$ and $t<c_{F}-c_{H}$, then from the proof of Proposition 1 we know that $\pi_{D_{H}}^{V}-\pi_{D_{H}}^{N}$ is given by (10) which corresponds to (14) for the linear demand case. Differentiating (14) in terms of $t$, we obtain (16), which is positive if $t<a-c_{H}+\widehat{c}_{F}-c_{F}$ and negative otherwise. Therefore, in this case, a decrease in $t$ has a positive impact on $\pi_{D_{H}}^{V}-\pi_{D_{H}}^{N}$ if $t$ is sufficiently large $\left(t>a-c_{H}+\widehat{c}_{F}-c_{F}\right)$ and a negative impact otherwise.

Proof of Proposition 3: We define the total welfare of country $H$ as the sum of the profits of $U_{H}$ and $D_{H}$, the surplus of its consumers, $C S_{H}$, and its tariff revenues, $T R_{H}^{V}$. Let us define $\Delta W_{H}$ as the difference in the total welfare of country $H$ with and without vertical FDI: $\Delta W_{H} \equiv W_{H}^{V}-W_{H}^{N}=\pi_{D_{H}}^{V}-\pi_{D_{H}}^{N}+\pi_{U_{H}}^{V}-\pi_{U_{H}}^{N}+C S_{H}^{V}-C S_{H}^{N}+T R_{H}^{V}-T R_{H}^{N}$. We have to distinguish among several cases:

A. If $c_{H}>c_{F}$, then $D_{F}$ sources the input domestically both with and without vertical FDI. In addition:

(a) if $t>c_{H}-\widehat{c}_{F}, D_{H}$ sources the input domestically both with and without vertical FDI (so there are no tariff revenues in country $H$ ). In this case, $\pi_{D_{H}}^{V}-\pi_{D_{H}}^{N}$ is given by (12) and it is positive, $\pi_{U_{H}}^{V}-\pi_{U_{H}}^{N}=\left(\frac{\left(a-c_{H}\right)^{2}}{4}-\frac{\left(a-\widehat{c}_{F}-t\right)^{2}}{4}\right)-\left(\frac{\left(a-c_{H}\right)^{2}}{4}-\frac{\left(a-c_{F}-t\right)^{2}}{4}\right)=\frac{\left(a-c_{F}-t\right)^{2}}{4}-\frac{\left(a-\widehat{c}_{F}-t\right)^{2}}{4}>0$, and $C S_{H}^{V}-C S_{H}^{N}=0$. Thus, $\Delta W_{H}=\frac{\left(a-\widehat{c}_{F}\right)^{2}}{4}-\frac{\left(a-c_{F}\right)^{2}}{4}>0$.

(b) if $c_{H}-c_{F}<t<c_{H}-\widehat{c}_{F}, D_{H}$ imports the input only under vertical FDI. In this case, $\pi_{D_{H}}^{V}-\pi_{D_{H}}^{N}=\frac{\left(a-\widehat{c}_{F}-t\right)^{2}}{4}-\frac{\left(a-c_{F}-t\right)^{2}}{4}+\frac{\left(a-\widehat{c}_{F}\right)^{2}}{4}-\frac{\left(a-c_{F}\right)^{2}}{4}>0, \pi_{U_{H}}^{V}-\pi_{U_{H}}^{N}=-\left(\frac{\left(a-c_{H}\right)^{2}}{4}-\right.$ $\left.\frac{\left(a-c_{F}-t\right)^{2}}{4}\right)<0, C S_{H}^{V}-C S_{H}^{N}=\frac{\left(a-\widehat{c}_{F}-t\right)^{2}}{8}-\frac{\left(a-c_{H}\right)^{2}}{8}>0$, and $T R_{H}^{V}-T R_{H}^{N}=t \frac{\left(a-\widehat{c}_{F}-t\right)}{2}>0$. Thus, $\Delta W_{H}=\frac{3\left(a-\widehat{c}_{F}-t\right)^{2}}{8}-\frac{3\left(a-c_{H}\right)^{2}}{8}+\frac{\left(a-\widehat{c}_{F}\right)^{2}}{4}-\frac{\left(a-c_{F}\right)^{2}}{4}+t \frac{\left(a-\widehat{c}_{F}-t\right)}{2}>0$. 
(c) if $t<c_{H}-c_{F}, D_{H}$ imports the input both with and without vertical FDI. In this case, $\pi_{D_{H}}^{V}-\pi_{D_{H}}^{N}$ is given by (12) and it is positive, $\pi_{U_{H}}^{V}-\pi_{U_{H}}^{N}=0, C S_{H}^{V}-C S_{H}^{N}=\frac{\left(a-\widehat{c}_{F}-t\right)^{2}}{8}-$ $\frac{\left(a-c_{F}-t\right)^{2}}{8}>0$, and $T R_{H}^{V}-T R_{H}^{N}=t\left(\frac{\left(a-\widehat{c}_{F}-t\right)}{2}-\frac{\left(a-c_{F}-t\right)}{2}\right)>0$. Thus, $\Delta W_{H}=\frac{3\left(a-\widehat{c}_{F}-t\right)^{2}}{8}-$ $\frac{3\left(a-c_{F}-t\right)^{2}}{8}+\frac{\left(a-\widehat{c}_{F}\right)^{2}}{4}-\frac{\left(a-c_{F}\right)^{2}}{4}+t\left(\frac{\left(a-\widehat{c}_{F}-t\right)}{2}-\frac{\left(a-c_{F}-t\right)}{2}\right)>0$.

B. If $c_{H}<c_{F}$, then:

(a) if $c_{H}<\widehat{c}_{F}<c_{F}$ and $t>c_{F}-c_{H}, D_{H}$ sources the input from $U_{H}$ and $D_{F}$ sources the input from $U_{F}$ both with and without vertical FDI; hence, there are no tariff revenues in country $H$. The analysis of this case is equivalent to that of case $\mathrm{A}(\mathrm{a})$ above.

(b) if $c_{H}<\widehat{c}_{F}<c_{F}$ and $\widehat{c}_{F}-c_{H}<t<c_{F}-c_{H}, D_{H}$ sources the input domestically both with and without vertical FDI, while $D_{F}$ imports the input only under no vertical FDI. In this case too, there are no tariff revenues in country $H$ and $\pi_{D_{H}}^{V}-\pi_{D_{H}}^{N}$ is given by (14) and it is positive, $\pi_{U_{H}}^{V}-\pi_{U_{H}}^{N}=\frac{\left(a-c_{F}-t\right)^{2}}{4}-\frac{\left(a-\widehat{c}_{F}-t\right)^{2}}{4}+\frac{\left(a-c_{F}\right)^{2}}{4}-\frac{\left(a-c_{H}-t\right)^{2}}{4}<0$, and $C S_{H}^{V}-C S_{H}^{N}=0$. Thus, $\Delta W_{H}=\left(\frac{\left(a-\widehat{c}_{F}\right)^{2}}{4}-\frac{\left(a-c_{H}-t\right)^{2}}{4}\right)-\left(\frac{\left(a-c_{H}-t\right)^{2}}{4}-\frac{\left(a-c_{F}\right)^{2}}{4}\right)$. We can see that $\Delta W_{H}$ is increasing in $t$ and solving $\Delta W_{H}=0$ for $t$, we get that $\Delta W_{H}<0$ if $t<t_{0}=a-c_{H}-\frac{\sqrt{2 a^{2}+c_{F}^{2}+\widehat{c}_{F}^{2}-2 a\left(c_{F}+\widehat{c}_{F}\right)}}{\sqrt{2}}$, and $\Delta W_{H}>0$ otherwise. It is easy to check that $\widehat{c}_{F}-c_{H}<t_{0}<c_{F}-c_{H}$ holds; hence, we can conclude that vertical FDI increases the total welfare in this region if and only if $\widehat{c}_{F}-c_{H}<t<t_{0}$.

(c) if $c_{H}<\widehat{c}_{F}<c_{F}$ and $t<\widehat{c}_{F}-c_{H}, D_{H}$ sources the input domestically both with and without vertical FDI, while $D_{F}$ imports the input both with and without vertical FDI. In this case, again, there are no tariff revenues in country $H$ and $\pi_{D_{H}}^{V}-\pi_{D_{H}}^{N}$ is given by (15) and it positive, $\pi_{U_{H}}^{V}-\pi_{U_{H}}^{N}=\left(\frac{\left(a-c_{F}-t\right)^{2}}{4}-\frac{\left(a-\widehat{c}_{F}-t\right)^{2}}{4}\right)+\left(\frac{\left(a-c_{F}\right)^{2}}{4}-\frac{\left(a-\widehat{c}_{F}\right)^{2}}{4}\right)<0$, and $C S_{H}^{V}-C S_{H}^{N}=0$. Thus, $\Delta W_{H}=\left(\frac{\left(a-c_{F}\right)^{2}}{4}-\frac{\left(a-\widehat{c}_{F}\right)^{2}}{4}\right)<0$.

(d) if $\widehat{c}_{F}<c_{H}<c_{F}, t>c_{F}-c_{H}$ and $t>c_{H}-\widehat{c}_{F}$, no downstream firm ever imports the input; hence, there are no tariff revenues in country $H$. This case is equivalent to case $\mathrm{A}(\mathrm{a})$ above.

(e) if $\widehat{c}_{F}<c_{H}<c_{F}$ and $c_{H}-\widehat{c}_{F}<t<c_{F}-c_{H}, D_{H}$ never imports the input and $D_{F}$ imports it only under no vertical FDI. This case is similar to case $\mathrm{B}(\mathrm{b})$ above, so $\Delta W_{H}<0$ if $t<t_{0}=a-c_{H}-\frac{\sqrt{2 a^{2}+c_{F}^{2}+\widehat{c}_{F}^{2}-2 a\left(c_{F}+\widehat{c}_{F}\right)}}{\sqrt{2}}$, and $\Delta W_{H}>0$ otherwise. However, it is easy to check that in this case, $t_{0}<c_{H}-\widehat{c}_{F}$, so we can conclude that $\Delta W_{H}>0$ within the entire interval under consideration.

(f) if $\widehat{c}_{F}<c_{H}<c_{F}, t>c_{F}-c_{H}$ and $t<c_{H}-\widehat{c}_{F}, D_{H}$ imports the input only under vertical FDI and $D_{F}$ never imports the input. The analysis of this case is equivalent to that of case $\mathrm{A}(\mathrm{b})$ above.

(g) if $\widehat{c}_{F}<c_{H}<c_{F}, t<c_{F}-c_{H}$ and $t<c_{H}-\widehat{c}_{F}, D_{F}$ imports the input only under no vertical FDI and $D_{H}$ imports it only under vertical FDI. In this case, $\pi_{D_{H}}^{V}-\pi_{D_{H}}^{N}$ is given by (14) and it is 
positive, $\pi_{U_{H}}^{V}-\pi_{U_{H}}^{N}=-\left(\frac{\left(a-c_{H}\right)^{2}}{4}-\frac{\left(a-c_{F}-t\right)^{2}}{4}+\frac{\left(a-c_{H}-t\right)^{2}}{4}-\frac{\left(a-c_{F}\right)^{2}}{4}\right)<0, C S_{H}^{V}-C S_{H}^{N}=\frac{\left(a-\widehat{c}_{F}-t\right)^{2}}{8}-$ $\frac{\left(a-c_{H}\right)^{2}}{8}>0$, and $T R_{H}^{V}-T R_{H}^{N}=t \frac{\left(a-\widehat{c}_{F}-t\right)^{2}}{4}>0$. Thus, $\Delta W_{H}=\left(\frac{3\left(a-\widehat{c}_{F}-t\right)^{2}}{8}-\frac{3\left(a-c_{H}\right)^{2}}{8}\right)+$ $\left(\frac{\left(a-\widehat{c}_{F}\right)^{2}}{4}-\frac{\left(a-c_{H}-t\right)^{2}}{4}\right)-\left(\frac{\left(a-c_{H}-t\right)^{2}}{4}-\frac{\left(a-c_{F}\right)^{2}}{4}\right)+t \frac{\left(a-\widehat{c}_{F}-t\right)}{2}$. Notice that $\Delta W_{H}$ is increasing in $t$ (as long as $t$ is not too large) and concave and solving $\Delta W_{H}=0$ for $t$, we get that $\Delta W_{H}<0$ if $t<t_{1}=\frac{1}{5}\left(3 a+\widehat{c}_{F}-4 c_{H}-\sqrt{\left.9 a^{2}-44 a \widehat{c}_{F}+26 \widehat{c}_{F}^{2}-20 a c_{F}+10 c_{F}^{2}+46 a c_{H}-8 \widehat{c}_{F} c_{H}-19 c_{H}^{2}\right)}\right)$, and $\Delta W_{H}>0$ otherwise. So we can conclude that vertical FDI reduces the total welfare of country $H$ if $t<\min \left\{t_{1}, c_{H}-\widehat{c}_{F}, c_{F}-c_{H}\right\}$, and increases it otherwise.

Proof of Proposition 4: We define $\Delta W_{F}$ as the difference in the total welfare of country $F$ with and without vertical FDI: $\Delta W_{F} \equiv W_{F}^{V}-W_{F}^{N}=\pi_{D_{F}}^{V}-\pi_{D_{F}}^{N}+\pi_{U_{F}}^{V}-\pi_{U_{F}}^{N}+C S_{F}^{V}-C S_{F}^{N}+$ $T R_{F}^{V}-T R_{F}^{N}$. The difference $\pi_{U_{F}}^{V}-\pi_{U_{F}}^{N}$ is always equal to 0 since $A$ is always set equal to $\pi_{U_{F}}^{N}$. We have to distinguish among several different cases:

A. If $c_{H}>c_{F}$, then $D_{F}$ never imports the input. This means that regardless of the value of $t$, we have $\pi_{D_{F}}^{V}-\pi_{D_{F}}^{N}=0 ; C S_{F}^{V}-C S_{F}^{N}=\frac{\left(a-\widehat{c}_{F}\right)^{2}}{8}-\frac{\left(a-c_{F}\right)^{2}}{8}>0$; and $T R_{F}^{V}-T R_{F}^{N}=0$. Thus, $\Delta W_{F}=C S_{F}^{V}-C S_{F}^{N}=\frac{\left(a-\widehat{c}_{F}\right)^{2}}{8}-\frac{\left(a-c_{F}\right)^{2}}{8}>0$.

B. If $c_{H}<c_{F}$, then:

(a) if $c_{H}<\widehat{c}_{F}<c_{F}$ and $t>c_{F}-c_{H}$, the welfare analysis coincides with case $\mathrm{A}$.

(b) if $c_{H}<\widehat{c}_{F}<c_{F}$ and $\widehat{c}_{F}-c_{H}<t<c_{F}-c_{H}$, we have $\pi_{D_{F}}^{V}-\pi_{D_{F}}^{N}=\frac{\left(a-c_{H}-t\right)^{2}}{4}-\frac{\left(a-c_{F}\right)^{2}}{4}>0$; $C S_{F}^{V}-C S_{F}^{N}=\frac{\left(a-\widehat{c}_{F}\right)^{2}}{8}-\frac{\left(a-c_{H}-t\right)^{2}}{8}>0 ; T R_{F}^{V}-T R_{F}^{N}=-t \frac{a-c_{H}-t}{2}<0$. Thus, $\Delta W_{F}=\frac{\left(a-\widehat{c}_{F}\right)^{2}}{8}-$ $\frac{\left(a-c_{H}-t\right)^{2}}{8}+\frac{\left(a-c_{H}-t\right)^{2}}{4}-\frac{\left(a-c_{F}\right)^{2}}{4}-t\left(\frac{\left(a-c_{H}-t\right)}{2}\right)$. This expression is decreasing (for $t$ not too large) and convex in $t$. In particular, $\Delta W_{F}<0$ if $t$ is large enough within the interval under consideration, namely, if $t>t_{2}=\frac{1}{5}\left(3 a-3 c_{H}-\sqrt{\left.9 a^{2}+10 a \widehat{c}_{F}-5 \widehat{c}_{F}^{2}-20 a c_{F}+10 c_{F}^{2}-8 a c_{H}+4 c_{H}^{2}\right)}\right)$. In short, $\Delta W_{F}<0$ if $\max \left\{t_{2}, \widehat{c}_{F}-c_{H}<t<c_{F}-c_{H}\right.$, and $\Delta W_{F}>0$ otherwise.

(c) if $c_{H}<\widehat{c}_{F}<c_{F}$ and $t<\widehat{c}_{F}-c_{H}$, we have $\left(\pi_{D_{F}}^{V}-\pi_{D_{F}}^{N}\right)=\frac{\left(a-\widehat{c}_{F}\right)^{2}}{4}-\frac{\left(a-c_{F}\right)^{2}}{4}>0$; $C S_{F}^{V}-C S_{F}^{N}=0$; and $T R_{F}^{V}-T R_{F}^{N}=0$. Thus, $\Delta W_{F}=\frac{\left(a-\widehat{c}_{F}\right)^{2}}{4}-\frac{\left(a-c_{F}\right)^{2}}{4}>0$.

(d) if $\widehat{c}_{F}<c_{H}<c_{F}, t>c_{F}-c_{H}$ and $t>c_{H}-\widehat{c}_{F}$, the welfare analysis of this case coincides with case A.

(e) if $\widehat{c}_{F}<c_{H}<c_{F}, t<c_{F}-c_{H}$ and $t>c_{H}-\widehat{c}_{F}$, the welfare analysis of this case coincides with case $\mathrm{B}(\mathrm{b})$. Thus, $\Delta W_{F}<0$ if $\max \left\{t_{2}, c_{H}-\widehat{c}_{F}<t<c_{F}-c_{H}\right.$, and $\Delta W_{F}>0$ otherwise.

(f) if $\widehat{c}_{F}<c_{H}<c_{F}, t>c_{F}-c_{H}$ and $t<c_{H}-\widehat{c}_{F}$, the welfare analysis coincides with case A.

(g) if $\widehat{c}_{F}<c_{H}<c_{F}, t<c_{F}-c_{H}$ and $t<c_{H}-\widehat{c}_{F}$, the welfare analysis coincides with case $\mathrm{B}(\mathrm{b})$. Thus, $\Delta W_{F}<0$ when $t_{2}<t<\min \left\{c_{F}-c_{H}, c_{H}-\widehat{c}_{F}\right\}$ and $\Delta W_{F}>0$ otherwise.

Proof of Proposition 5: We define the change in the joint total welfare as $\Delta W_{T} \equiv \Delta W_{H}+$ $\Delta W_{F}$. It is straightforward to show, first, that if $c_{H}>c_{F}, \Delta W_{T}>0$, given that in this region, 
vertical FDI always increases welfare in each of the two countries. When $c_{H}<c_{F}$, however, we have to distinguish among the following possible cases:

(a) if $c_{H}<\widehat{c}_{F}<c_{F}$ and $t>c_{F}-c_{H}$, then $\Delta W_{T}=\frac{3\left(a-\widehat{c}_{F}\right)^{2}}{8}-\frac{3\left(a-c_{F}\right)^{2}}{8}>0$.

(b) if $c_{H}<\widehat{c}_{F}<c_{F}$ and $\widehat{c}_{F}-c_{H}<t<c_{F}-c_{H}$, then $\Delta W_{T}=\frac{3\left(a-\widehat{c}_{F}\right)^{2}}{8}-\frac{3\left(a-c_{H}-t\right)^{2}}{8}-$ $t\left(\frac{\left(a-c_{H}-t\right)}{2}\right)$. It is direct to see that this expression is increasing and convex in $t$ and that $\Delta W_{T}<0$ if $t$ is low enough within the interval under consideration, namely, if $\widehat{c}_{F}-c_{H}<$ $t<\min \left\{t_{3}, c_{F}-c_{H}\right\}$, where $t_{3}=-a+c_{H}+\sqrt{\left.a^{2}+6 a \widehat{c}_{F}-3 \widehat{c}_{F}^{2}-8 a c_{H}+4 c_{H}^{2}\right)}$, and $\Delta W_{T}>0$ otherwise.

(c) if $c_{H}<\widehat{c}_{F}<c_{F}$ and $t<\widehat{c}_{F}-c_{H}$, then $\Delta W_{T}=0$.

(d) if $\widehat{c}_{F}<c_{H}<c_{F}, t>c_{F}-c_{H}$ and $t>c_{H}-\widehat{c}_{F}$, then $\Delta W_{T}=\frac{3\left(a-\widehat{c}_{F}\right)^{2}}{8}-\frac{3\left(a-c_{F}\right)^{2}}{8}>0$.

(e) if $\widehat{c}_{F}<c_{H}<c_{F}, t<c_{F}-c_{H}$ and $t>c_{H}-\widehat{c}_{F}$, the welfare analysis of this case coincides with case (b).

(f) if $\widehat{c}_{F}<c_{H}<c_{F}, t>c_{F}-c_{H}$ and $t<c_{H}-\widehat{c}_{F}$, then $\Delta W_{T}=W_{T}^{V}-W_{T}^{N}=\frac{3\left(a-\widehat{c}_{F}-t\right)^{2}}{8}-$ $\frac{3\left(a-c_{H}\right)^{2}}{8}+\frac{3\left(a-\widehat{c}_{F}\right)^{2}}{8}-\frac{3\left(a-c_{F}\right)^{2}}{8}+t \frac{\left(a-\widehat{c}_{F}-t\right)}{2}>0$.

(g) if $\widehat{c}_{F}<c_{H}<c_{F}, t<c_{F}-c_{H}$ and $t<c_{H}-\widehat{c}_{F}$, then $\Delta W_{T}=\left(\frac{3\left(a-\widehat{c}_{F}-t\right)^{2}}{8}-\frac{3\left(a-c_{H}\right)^{2}}{8}\right)+$ $\left(\frac{3\left(a-\widehat{c}_{F}\right)^{2}}{8}-\frac{3\left(a-c_{H}-t\right)^{2}}{8}\right)+t\left(\frac{\left(a-\widehat{c}_{F}-t\right)}{2}-\frac{\left(a-c_{H}-t\right)}{2}\right)>0$.

\section{Proof of Proposition 6}

A. Assume that $\widehat{c}_{F}<c_{F}<\widehat{c}_{H}<c_{H}$. In this case, $D_{F}$ always sources the input from $U_{F}$, while $D_{H}$ might though source it from $U_{H}$ or from $U_{F}$ depending on the level of $t$. Because of this, we need to distinguish among the following cases:

(i) $t>c_{H}-c_{F}$ (this implies that $t>\widehat{c}_{H}-c_{F}$ also holds):

Under domestic acquisition, $D_{H}$ insources the input from $U_{H}$ at $\widehat{c}_{H}$; hence, its domestic profits are $\widetilde{\pi}_{D_{H}}^{H}=\frac{\left(a-\widehat{c}_{H}\right)^{2}}{4} . U_{H}$ makes no sales to country $F$. Moreover, $A$ is equal to the profits of $U_{H}$ under no acquisition. In particular, since under no acquisition $U_{H}$ makes sales only to country $H$ and the case of no acquisition coincides with the case of no vertical FDI analyzed in Section 4 , it follows that $A_{H}^{*}=\pi_{U_{H}}^{H}=\frac{\left(a-c_{H}\right)^{2}}{4}-\frac{\left(a-c_{F}-t\right)^{2}}{4}$. Under vertical FDI, we know from Section 4 that $D_{H}$ sources the input from $U_{H}$. It follows that

$$
\begin{aligned}
\pi_{D_{H}}^{D}-\pi_{D_{H}}^{V} & =\frac{\left(a-\widehat{c}_{H}\right)^{2}}{4}-\frac{\left(a-c_{H}\right)^{2}}{4}+\frac{\left(a-c_{F}-t\right)^{2}}{4}-\frac{\left(a-\widehat{c}_{F}-t\right)^{2}}{4} \\
+\frac{\left(a-\widehat{c}_{F}\right)^{2}}{4}-\frac{\left(a-c_{F}\right)^{2}}{4} & =\frac{1}{4}\left(\left(\widehat{c}_{H}-c_{H}\right)\left(2 a+\widehat{c}_{H}+c_{H}-2 \widehat{c}_{F}-2 c_{F}-2 t\right) .\right.
\end{aligned}
$$

The above difference is always negative because the first parenthesis is negative and, given our assumptions, $a>2 c_{H}-c_{F}$, which implies that the second parenthesis is positive. It follows that 
$D_{H}$ prefers to acquire $U_{F}$.

(ii) $\widehat{c}_{H}-c_{F}<t<c_{H}-c_{F}$ :

Under domestic acquisition, similarly to case (i) above, $D_{H}$ insources the input. Thus, its domestic profits are given again by $\widetilde{\pi}_{D_{H}}^{H}=\frac{\left(a-\widehat{c}_{H}\right)^{2}}{4}$. In the case of no acquisition now, $U_{H}$ makes no sales and thus no profits. This implies that $A_{H}^{*}=0$. In turn, $D_{H}$ 's profits under domestic acquisition are now $\pi_{D_{H}}^{D}=\frac{\left(a-\widehat{c}_{H}\right)^{2}}{4}$. Under vertical FDI, $D_{H}$ sources the input from $U_{F}$ since $t<c_{H}-c_{F}$ implies that $t<c_{H}-\widehat{c}_{F}$. The comparison of $D_{H}$ 's profits under domestic acquisition and under cross-border acquisition coincides with (17) above. Therefore, we have again that $\pi_{D_{H}}^{D}<\pi_{D_{H}}^{V}$, and thus that $D_{H}$ prefers to acquire $U_{F}$.

(iii) $t<\widehat{c}_{H}-c_{F}$ :

Under domestic acquisition as well as under no acquisition, $D_{H}$ sources the input from $U_{F}$. Therefore, $A_{H}^{*}=0$ and $D_{H}$ 's total profits under domestic acquisition are again: $\pi_{D_{H}}^{D}=\widetilde{\pi}_{D_{H}}^{H}=$ $\frac{\left(a-\widehat{c}_{H}\right)^{2}}{4}$. Under vertical FDI, $D_{H}$ sources the input from $U_{F}$ (note that $t<\widehat{c}_{H}-c_{F}$ implies that $t<c_{H}-\widehat{c}_{F}$ also holds). The resulting comparison coincides again with (17) above. As a result, we can conclude that $D_{H}$ prefers to acquire $U_{F}$.

B. Assume now that $\widehat{c}_{F}<\widehat{c}_{H}<c_{F}<c_{H}$. We need to distinguish among the following cases:

(i) $t>c_{H}-c_{F}$ and $t>c_{F}-\widehat{c}_{H}$ :

In this case, both downstream firms outsource the input under domestic acquisition and also under no acquisition. Under vertical FDI, $D_{F}$ does not import the input. Moreover, $D_{H}$ sources the input from $U_{F}$ under vertical FDI if and only if $t<c_{H}-\widehat{c}_{F}$. Both in the case in which $t<c_{H}-\widehat{c}_{F}$ as well as when $t>c_{H}-\widehat{c}_{F}$. The comparison of $D_{H}$ 's profits with domestic acquisition and with vertical FDI coincides with (17). Therefore, in this case too, $D_{H}$ prefers cross-border acquisition rather than domestic acquisition.

(ii) $c_{F}-\widehat{c}_{H}<t<c_{H}-c_{F}$ :

It is direct to see that the comparison of $D_{H}$ 's profits under domestic acquisition and under vertical FDI is exactly the same as in case A(ii) above. Hence, in this case too, the home downstream firm prefers vertical FDI.

(iii) $t>c_{H}-c_{F}$ and $t<c_{F}-\widehat{c}_{H}$ :

$D_{H}$ sources the input from $U_{H}$ both under domestic acquisition and no acquisition. In contrast to the cases above, $D_{F}$ now imports the input from $U_{H}$ under domestic acquisition. Therefore, under domestic acquisition, $\widetilde{\pi}_{D_{H}}^{H}=\frac{\left(a-\widehat{c}_{H}\right)^{2}}{4}$ and $\widetilde{\pi}_{U_{H}}^{F}=\frac{\left(a-\widehat{c}_{H}-t\right)^{2}}{4}-\frac{\left(a-c_{F}\right)^{2}}{4}$, while $A_{H}^{*}=\frac{\left(a-c_{H}\right)^{2}}{4}-$ $\frac{\left(a-c_{F}-t\right)^{2}}{4}$ since under no acquisition, $U_{H}$ sells the input only domestically. Under vertical FDI, $D_{F}$ does not import the input and $D_{H}$ sources the input from $U_{F}$ only under vertical FDI (note that $t<c_{F}-\widehat{c}_{H}$ guarantees that $t<c_{H}-\widehat{c}_{F}$ also holds). Comparing the profits of $D_{H}$ under 
domestic acquisition and under cross-border acquisition, we have:

$\pi_{D_{H}}^{D}-\pi_{D_{H}}^{V}=\left[\frac{\left(a-\widehat{c}_{H}-t\right)^{2}}{4}+\frac{\left(a-\widehat{c}_{H}\right)^{2}}{4}-\frac{\left(a-c_{H}\right)^{2}}{4}+\frac{\left(a-c_{F}-t\right)^{2}}{4}\right]-\left[\frac{\left(a-\widehat{c}_{F}-t\right)^{2}}{4}+\frac{\left(a-\widehat{c}_{F}\right)^{2}}{4}\right]$.

It is direct to see that the expression within the second bracket is larger than the expression within the first bracket. Therefore, $\pi_{D_{H}}^{D}<\pi_{D_{H}}^{V}$, i.e., cross-border acquisition is preferred to domestic acquisition.

(iv) $t<c_{H}-c_{F}$ and $t<c_{F}-\widehat{c}_{H}$ :

$D_{H}$ imports the input under no domestic acquisition but not under domestic acquisition. In contrast, $D_{F}$ imports the input under domestic acquisition but not under no acquisition. Therefore, $A_{H}^{*}=0$. Under vertical FDI, $D_{F}$ does not import the input and $D_{H}$ sources the input from $U_{F}$ both under vertical FDI and no vertical FDI (note that $t<c_{H}-c_{F}$ implies that $t<c_{H}-\widehat{c}_{F}$ holds).

The comparison of the profits of $D_{H}$ under domestic acquisition and under cross-border acquisition results in (18). It is easy to see that, provided that $t$ has to be lower than $a-c_{F}$, then, $\partial\left(\pi_{D_{H}}^{D}-\pi_{D_{H}}^{V}\right) / \partial t>0$ if $a-c_{F}-\left(\widehat{c}_{H}-\widehat{c}_{F}\right)<t<a-c_{F}$. Moreover, when $t=a-c_{F}$, $\pi_{D_{H}}^{D}-\pi_{D_{H}}^{V}<0$, which implies that a cross-border acquisition is superior in the entire interval. On the other hand, if $t<a-c_{F}-\left(\widehat{c}_{H}-\widehat{c}_{F}\right)$, then $\partial\left(\pi_{D_{H}}^{D}-\pi_{D_{H}}^{V}\right) / \partial t<0$ holds. So if we get that when $t=0$, the difference $\pi_{D_{H}}^{D}-\pi_{D_{H}}^{V}<0$, this would imply that the difference is negative in the entire interval. It is easy to check that this is the case as long as the demand intercept $a$ is not too low, in particular, as long as $a>\left(\widehat{c}_{H}+\widehat{c}_{F}\right)-\frac{c_{H}+c_{F}}{2}$. Therefore, we conclude that (under the previous assumption) a cross-border acquisition is preferred to domestic acquisition. C. Assume that $\widehat{c}_{H}<c_{H}<\widehat{c}_{F}<c_{F}$. In this case, $D_{H}$ always sources the input from $U_{H}$. We need to distinguish among the following cases:

(i) $t>c_{F}-\widehat{c}_{H}$ :

In this case, no firm ever imports the input. Therefore, the comparison in this case is equivalent to the one in case $\mathrm{A}(\mathrm{i})$.

(ii) $c_{F}-c_{H}<t<c_{F}-\widehat{c}_{H}$ :

It is direct to see that the comparison of $D_{H}$ 's profits under domestic acquisition and under vertical FDI is exactly the same as in case B(iii). Hence, it is easy to see that, provided that $a$ has to be greater than $c_{F}+t, \partial\left(\pi_{D_{H}}^{D}-\pi_{D_{H}}^{V}\right) / \partial t<0$. When $t=0$, the difference $\pi_{D_{H}}^{D}-\pi_{D_{H}}^{V}$ is negative, which implies that it must be negative within the entire interval under consideration. Therefore, a cross-border acquisition is superior in this case to a domestic acquisition.

(iii) $\widehat{c}_{F}-c_{H}<t<c_{F}-c_{H}$ 
$D_{H}$ never imports the input while $D_{F}$ imports the input both under domestic and no domestic acquisition. Under vertical FDI, neither $D_{H}$ nor $D_{F}$ import the input. Therefore, comparing the profits of $D_{H}$ under domestic acquisition and under vertical FDI, we have:

$$
\begin{aligned}
\pi_{D_{H}}^{D}-\pi_{D_{H}}^{V}= & \left(\frac{\left(a-\widehat{c}_{H}\right)^{2}}{4}+\frac{\left(a-c_{F}-t\right)^{2}}{4}\right)+\left(\frac{\left(a-\widehat{c}_{H}-t\right)^{2}}{4}-\frac{\left(a-\widehat{c}_{F}-t\right)^{2}}{4}\right)+ \\
& \left(\frac{\left(a-c_{H}\right)^{2}}{4}-\frac{\left(a-\widehat{c}_{F}\right)^{2}}{4}\right) .
\end{aligned}
$$

The expressions within the three parenthesis are clearly positive. In other words, in this case, a domestic acquisition is preferred to a cross-border acquisition.

(iv) $t<\widehat{c}_{F}-c_{H}$.

$D_{H}$ never imports the input while $D_{F}$ imports the input both under domestic and no domestic acquisition. Under vertical FDI, both $D_{H}$ and $D_{F}$ sources the input from $U_{H}$. Therefore, $D_{H}$ 's profits when it undertakes vertical FDI are $\pi_{D_{H}}^{V}=\frac{\left(a-\widehat{c}_{F}-t\right)^{2}}{4}$. Therefore, comparing the profits of $D_{H}$ under domestic acquisition and under cross-border acquisition, we have:

$\pi_{D_{H}}^{D}-\pi_{D_{H}}^{V}=\frac{\left(a-\widehat{c}_{H}\right)^{2}}{4}-\frac{\left(a-c_{H}\right)^{2}}{4}+\frac{\left(a-\widehat{c}_{H}-t\right)^{2}}{4}-\frac{\left(a-\widehat{c}_{F}-t\right)^{2}}{4}+\frac{\left(a-c_{F}-t\right)^{2}}{4}-\frac{\left(a-c_{H}-t\right)^{2}}{4}$.

The above is clearly positive. Therefore in this case too, a domestic acquisition is preferred to a cross-border acquisition.

D. Assume that $\widehat{c}_{H}<\widehat{c}_{F}<c_{H}<c_{F}$.

(i) $t>c_{F}-\widehat{c}_{H}$

Under both domestic acquisition and no acquisition, $D_{H}$ sources the input from $U_{H}$. $D_{F}$ instead sources the input from $U_{F}$ under both domestic acquisition and no acquisition. Under vertical FDI, $U_{F}$ sources the input only to $D_{F}$. The comparison is thus:

$\pi_{D_{H}}^{D}-\pi_{D_{H}}^{V}=\frac{\left(a-\widehat{c}_{H}\right)^{2}}{4}-\frac{\left(a-c_{H}\right)^{2}}{4}+\frac{\left(a-c_{F}-t\right)^{2}}{4}-\frac{\left(a-\widehat{c}_{F}-t\right)^{2}}{4}-\frac{\left(a-\widehat{c}_{F}\right)^{2}}{4}+\frac{\left(a-c_{F}\right)^{2}}{4}$.

It is easy to show that within the region under consideration, the above difference is negative and thus a cross-border acquisition is more profitable than a domestic one. Notice first that the above expression is linear and increasing in $t$. Second, we know that $t<a-c_{F}$, and evaluating $\pi_{D_{H}}^{D}-\pi_{D_{H}}^{V}$ in $t=a-c_{F}$ we check that the difference is negative, which proves that it is negative in the entire interval under consideration, that is, a cross border acquisition is superior to a domestic acquisition.

(ii) $t>c_{F}-c_{H}$ and $t<c_{H}-\widehat{c}_{F}$ : 
This case is similar to case $\mathrm{D}(\mathrm{i})$ above. The only difference is that, under vertical FDI, $D_{H}$ sources the input domestically in case $\mathrm{D}(\mathrm{i})$ and insources the input in $\mathrm{D}(\mathrm{ii})$. But $D_{H}$ 's profits are the same in both cases. As a result, the comparison is the same as in case $\mathrm{D}(\mathrm{i})$ above, so the above difference is negative.

(iii) $t<c_{F}-c_{H}$ (which also implies $t<c_{F}-\widehat{c}_{H}$ ) and $t>c_{H}-\widehat{c}_{F}$ :

It is direct to see that this case coincides with case $\mathrm{C}$ (iii) and thus a domestic acquisition is preferred to a cross-border acquisition.

(iv) $t<c_{F}-c_{H}$ (this also implies $t<c_{F}-\widehat{c}_{H}$ ) and $t<c_{H}-\widehat{c}_{F}$ :

This case is similar to case $\mathrm{C}\left(\right.$ iii) above. The only difference is that, under vertical FDI, $D_{H}$ sources the input domestically as in case $\mathrm{D}(\mathrm{iv})$ and insources the input as in $\mathrm{C}(\mathrm{iii})$. But $D_{H}$ 's profits are the same in both cases. As a result, the comparison is the same as in $\mathrm{C}(\mathrm{iii})$ above, and thus a domestic acquisition is preferred to a cross-border acquisition.

\section{References}

Alfaro, L. and A. Charlton (2009), "Intra-industry Foreign Direct Investment," American Economic Review, 99, 2096-2119.

Antras, P. (2003), "Firms, Contracts, and Trade Structure," Quarterly Journal of Economics, $118,1375-418$.

Antras, P. and E. Helpman (2004), "Global Sourcing," Journal of Political Economy, 112, $552-580$.

Antras, P. and E. Rossi-Hansberg (2009), "Organizations and Trade," Annual Review of Economics, 1, 43-64.

Arnold, M. and B. Javorcik (2009), "Gifted Kids or Pushy Parents? Foreign Direct Investment and Plant Productivity in Indonesia," Journal of International Economics, 79, 42-53.

Atalay, E., A. Hortacsu, and C. Shyverson (2014), "Vertical Integration and Input Flows," American Economic Review, 104, 1120-1148.

Bas, M. and J. Carluccio (2015), "The Impact of Worker Bargaining Power on the Organization of Global Firms," Journal of International Economics, 96, 162-181.

Beladi, H. and A. Mukherjee (2012), "Market Structure and Strategic Bi-sourcing," Journal of Economic Behavior and Organization, 82, 210-219.

Berry, H. and A. Kaul (2015), "Global Sourcing and Foreign Knowledge Seeking," Management Science, 61, 1052-1071.

Bjorvatn, K. (2004), "Economic Integration and the Profitability of Cross-border Mergers 
and Acquisitions," European Economic Review, 48, 1211-1226.

Brainard, L. (1997), "An Empirical Assessment of the Proximity-Concentration Trade-off between Multinational Sales and Trade," American Economic Review, 87, 520-544.

Breinlich, H., Nocke, V. and N. Schutz (2016), "International Aspects of Merger Policy: A Survey," International Journal of Industrial Organization, forthcoming.

Carr, D., J. Markusen and K. Maskus (2001), "Estimating the Knowledge Capital Model of the Multinational Enterprise," American Economic Review, 91, 693-708.

Chen, Y., J. Ishikawab and Y. Zhihao (2004), "Trade Liberalization and Strategic Outsourcing," Journal of International Economics, 63, 419-436.

Du, J., Y. Lu, and Z. Tao (2006), "Why do Firms Conduct Bi-sourcing?" Economics Letters, 92, 245-249.

Du, J., Y. Lu, and Z. Tao (2009), "Bi-sourcing in the Global Economy," Journal of International Economics, 77, 215-222.

Feenstra, R. (1998), "Integration of Trade and Disintegration of Production in the Global Economy," Journal of Economic Perspectives, 12, 31-50.

Feinberg, S. and M. Keane (2001), "U.S.-Canada Trade Liberalization and MNC Production Location," Review of Economics and Statistics, 83, 118-132.

Girma, S., H. Gorg and M. Pisu (2008), "Exporting, Linkages and Productivity Spillovers from Foreign Direct Investment', Canadian Journal of Economics, 41, 320-340.

Grossman, G. and O. Hart (1986), "The Costs and Benefits of Ownership: A Theory of Vertical and Lateral Integration," Journal of Political Economy, 94, 691-719.

Grossman, G. and E. Helpman (2003), "Outsourcing versus FDI in Industry Equilibrium," Journal of European Economic Association, 1, 317-327.

Grossman, G. and E. Helpman (2005), "Outsourcing in a Global Economy," Review of Economic Studies, 72, 135-159.

Hanson, G., R. Mataloni and M. Slaughter (2005), "Vertical Production Networks in Multinational Firms," Review of Economics and Statistics, 664-678.

Hart, O. and J. Moore (1990), "Property Rights and the Nature of the Firm," Journal of Political Economy, 98, 1119-1158.

Hayakawa, K. and T. Matsura (2015), "Trade Liberalization in Asia and FDI Strategies in Heterogeneous Firms: Evidence from Japanese Firm-level Data," Oxford Economic Papers, 67, 494-513.

Helpman, E. (1984), “A Simple Theory of International Trade with Multinational Corporations," Journal of Political Economy, 92, 451-471. 
Helpman, E. and P. Krugman (1985), Market Structure and Foreign Trade, MIT Press: Cambridge, MA.

Horn, H. and J. Levinsohn (2001), "Merger Policies and Trade Liberalisation," Economic Journal, 111, 244-276.

Hummels, D., J. Ishiib and K.- M. Yic (2001), "The Nature and Growth of Vertical Specialization in World Trade," Journal of International Economics, 54, 75-96.

Inderst, R. (2010), "Models of Vertical Market Relations," International Journal of Industrial Organization, 28, 341-344.

Keith, H. and J. Ries (1997), "International Mergers and Welfare under Decentralized Competition Policy," Canadian Journal of Economics, 30, 1104-1123.

Markusen, J. (2002), Multinational Firms and the Theory of International Trade, MIT Press, Cambridge, MA.

Mathewson, F. and R. Winter (1987), "The Competitive Effects of Vertical Agreements: Comment," American Economic Review, 77, 1057-62.

Mattoo, A., M. Olarreaga and K. Saggi (2004), "Mode of Foreign Entry, Technology Transfer, and FDI Policy," Journal of Development Economics, 75, 95-111.

Miklós-Thal, J., P. Rey and T. Vergé (2010), "Vertical Relations," International Journal of Industrial Organization, 28, 345-349.

Motta, M. and G. Norman (1996), "Does Economic Integration Cause Foreign Direct Investment?" International Economic Review, 37, 757-783.

Newman, C., J. Rand, T. Talbot and F. Tarp (2015), "Technology Transfers, Foreign Investment and Productivity Spillovers," European Economic Review, 76, 168-187.

Nickerson, J. and R. Vanden Bergh (1999), "Economizing in a Context of Strategizing: Governance Mode choice in Cournot Competition," Journal of Economic Behavior and Organization, 40, 1-15.

O’Brien, D. and G. Shaffer (1997), "Nonlinear Supply Contracts, Exclusive Dealing, and Equilibrium Market Foreclosure," Journal of Economics and Management Strategy, 6, 755-785.

Ornelas, E. and J. Turner (2008), "Trade liberalization, Outsourcing, and the Hold-up Problem," Journal of International Economics, 74, 225-241.

Qiu, L. and B. Spencer (2002), "Keiretsu and Relationship-specific Investment: Implications for Market-opening Trade Policy," Journal of International Economics, 58, 49-79.

Petit, M. L. and F. Sanna-Randaccio (2000), "Endogenous R\&D and Foreign Direct Investment in International Oligopolies," International Journal of Industrial Organization, 18, 339-367. 
Ramondo, N., V. Rappoprt, and K. J. Ruhl (2016), "Intrafirm trade and vertical fragmentation in U.S. multinational corporations", Journal of International Economics, 98, 51-59.

Shy, O. and R. Stenbacka (2003), "Strategic Outsourcing," Journal of Economic Behavior and Organization, 50, 203-244.

Slaughter, M. (2000), "Production Transfer within Multinational Enterprises and American Wages," Journal of International Economics, 50, 449-472.

Spencer, B. (2005), "International Outsourcing and Incomplete Contracts," Canadian Journal of Economics, 38, 1107-1135.

Stenbacka, R. and M. Tombak (2012), "Make and Buy: Balancing Bargaining Power," Journal of Economic Behavior and Organization, 81, 391-402.

UNCTAD (2001), World Investment Report 2001, United Nations, Geneva.

UNCTAD (2006), World Investment Report 2006, United Nations, Geneva.

UNCTAD (2014), World Investment Report 2015, United Nations, Geneva.

Yeaple, S. (2003), "The Role of Skill Endowments in the Structure of U.S. Outward Foreign Direct Investment," Review of Economics and Statistics, 85, 726-734.

Yeats, A. (2001), "Just How Big is Global Production Sharing?" in S. Arndt and H. Kierzkowski. (eds.), Fragmentation: New Production Patterns in the World Economy, Oxford University Press, Oxford, UK.

Yi, K.-M. (2003), "Can Vertical Specialization Explain the Growth of World Trade?” Journal of Political Economy, 111, 52-102. 


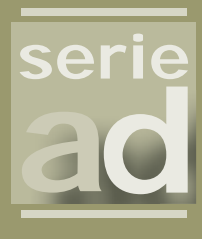

\section{I vie}

Guardia Civil, 22 - Esc. 2, 1 은

46020 Valencia - Spain

Phone: +34963190050

Fax: +34 963190055

Website: www.ivie.es

E-mail: publicaciones@ivie.es 